\title{
SOLO E ÁGUAS SUBTERRÂNEAS CONTAMINADAS PELA DEPOSIÇÃO DE RESÍDUOS SÓLIDOS URBANOS: O CASO DO VAZADOURO DE TATUÍ (SP)
}

\author{
Manoel Gomes dos SANTOS FILHO \\ Ricardo HIRATA \\ Mariana Bernardino LUIZ \\ Bruno CONICELLI
}

\begin{abstract}
RESUMO
Este trabalho determina a extensão da contaminação do solo e da água subterrânea impactados pela deposição incorreta de resíduos sólidos urbanos, bem como a localização de material enterrado, a partir de métodos geofísicos de eletrorresistividade e eletromagnético e da coleta e monitoramento da água subterrânea no Vazadouro Municipal de Tatuí (SP). Operando de 1991 a 2014, o empreendimento ocupou uma área de 14,87 ha e recebeu diariamente $40 \mathrm{t}$ de resíduos sólidos de residências, comércios e serviços da cidade. A partir das análises químicas das águas subterrâneas de 12 poços de monitoramento, em seis campanhas entre junho de 2000 e janeiro de 2001, foi possível estabelecer que a pluma contaminante é restrita à área do empreendimento ou se estendeu muito próxima a ele. As sondagens elétricas verticais identificaram a ocorrência de uma camada resistiva interpretada como um aquitarde e o caminhamento eletromagnético indutivo detectou anomalias de condutividade elétrica relacionadas ao lixo enterrado. Entretanto, o uso do Geonics EM34 não permitiu uma boa caracterização da contaminação das águas subterrâneas, que se encontra em profundidades maiores que $8 \mathrm{~m}$. A potenciometria do aquífero está condicionada à pluviometria e às características fisiográficas da área do lixão, onde se vê claramente que o resíduo é mais permeável à infiltração das chuvas. Notadamente, as águas subterrâneas não impactadas têm um perfil geoquímico de $\mathrm{Na-Ca-HCO3} \mathrm{e} \mathrm{as}$ contaminadas, Na-Cl-(NO3). A principal conclusão deste trabalho é que a despeito da rapidez e facilidade dos métodos geofísicos, estes não foram suficientes para uma boa caracterização da pluma de contaminação no aquífero, pois os terrenos possuem baixa permeabilidade e as massas de lixos foram depositadas de forma heterogênea e dispersa. Assim, o uso integrado de ambas as técnicas é eficaz para estudos de casos similares.
\end{abstract}

Palavras-chave: Sistema Aquífero Tubarão; Contaminação de água subterrânea; Lixão; Resíduos sólidos municipais; Métodos geofísicos.

\section{ABSTRACT}

SOIL AND GROUNDWATER CONTAMINATION BY AN OPEN DUMP: THE CASE STUDY OF TATUÍ (SP, BRAZIL). This study evaluates the extent of contamination of soil and groundwater impacted by the inappropriate deposition of municipal solid waste, as well as investigates the location of buried material, using electrical resistivity and electromagnetic geophysical methods, and groundwater monitoring data from 12 wells drilled in the open dump of the city of Tatuí (SP, Brazil). From 1991 to 2014, 40 tons/day of solid waste from the city residences and services was disposed of in the open dump, which comprises an area of $14.87 \mathrm{ha}$. Based on the chemical analysis of groundwater samples from monitoring wells in six campaigns, from June 2000 to January 2001, it was possible to determine that the groundwater contaminant plume is restricted to the area of the dump or extended to an area very close to it. Vertical electrical sounding method identified a resistive layer that was interpreted as an aquitard, and 
electromagnetic tomography detected anomalies related to the buried waste. However, it was not possible to obtain a good characterization of contamination of groundwater from depths greater than $8 \mathrm{~m}$ using Geonics EM34. The aquifer potentiometry is influenced by rainfall and physiographic characteristics of the dump area, where it is clearly seen that the waste is more permeable to the rainfall infiltration than the soil. Notably, non-contaminated groundwater has a Na-Ca-HCO3 geochemical signature, whereas contaminated groundwater has a Na-Cl-(NO3) signature. The main conclusion of this study is that although indirect methods were easier to use, they could not provide a good characterization of the contamination of the saturated zone, especially in areas of low permeability and heterogeneous and dispersed deposition of masses of waste. Thus, the simultaneous use of both techniques seems to be useful for similar case studies.

Keywords: Tubarão Aquifer System; Groundwater contamination; Open dump; Municipal solid waste; Geophysical method.

\section{INTRODUÇÃO}

Diante da necessidade de destinar o lixo urbano gerado pela população de 100 mil habitantes de Tatuí (SP), foi iniciada em janeiro de 1991 a deposição de resíduos sólidos urbanos em uma antiga cava abandonada de argila, ocupando uma área de 14,87 ha (Figura 1), em um empreendimento conhe- cido na região como Vazadouro. Este lixão recebeu uma média de 40 t/dia de resíduos sólidos diversos do recolhimento domiciliar, comercial, varrição de vias pública, hospitalar e industrial, mas não houve um controle preciso de sua origem ou de sua quantidade. O Vazadouro foi fechado em 2014 e os resíduos do município passaram a ser descartados em um aterro sanitário no município de Iperó.

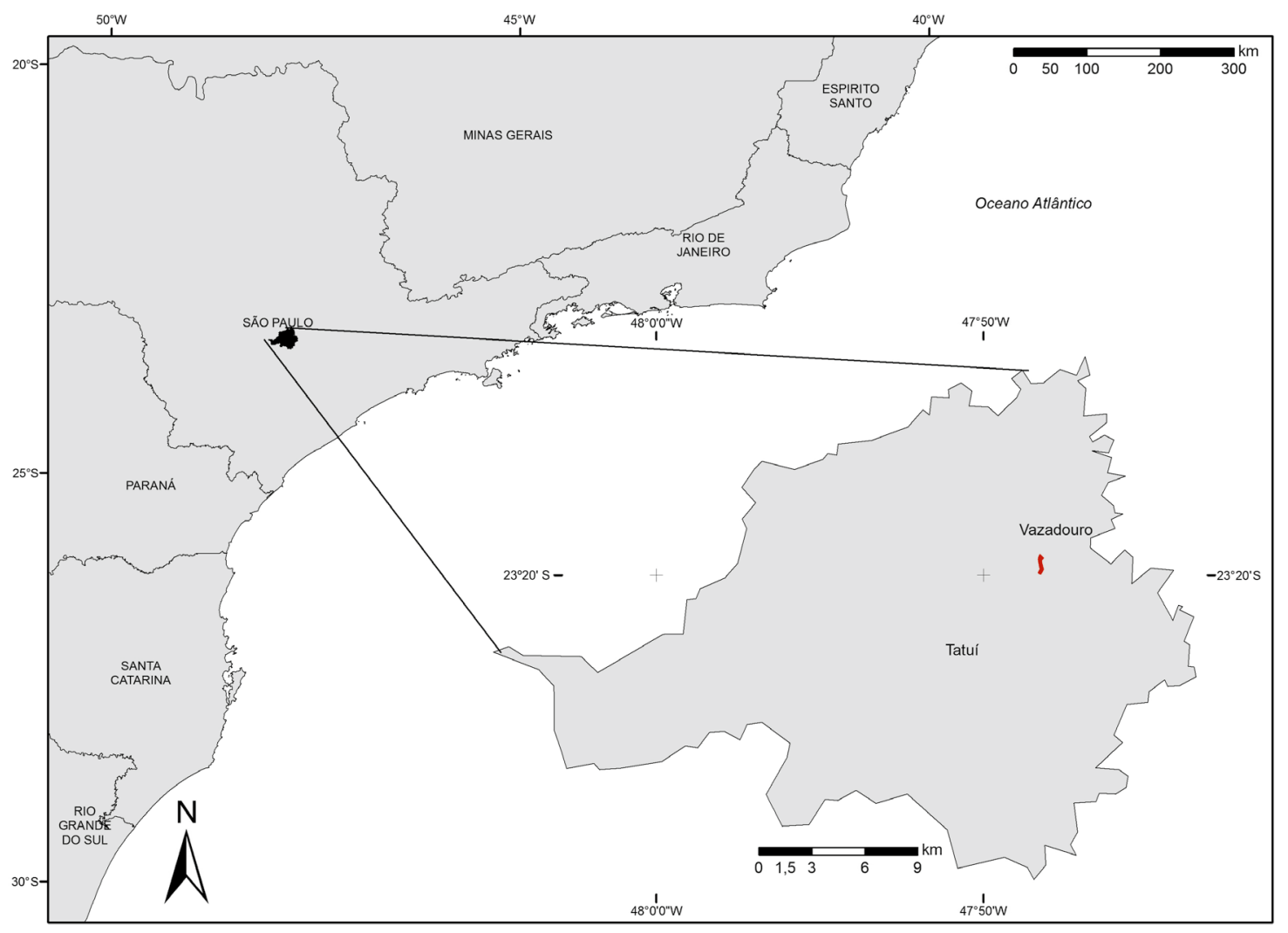

FIGURA 1 - Localização do Vazadouro no município de Tatú e no estado de São Paulo. 
A deposição de resíduos sólidos diretamente no solo causa a sua contaminação e a das águas subterrâneas, associada aos lixiviados que percolam o resíduo sólido (FREEZE \& CHERRY 1979, HUTCHINSON \& BARTA 2000, SOUPIOS et al. 2007, OLLA et al. 2015, SIDHARDHAN et al. 2015, HIRATA et al. 2015).

O presente estudo teve como objetivo a caracterização de solo e águas subterrâneas contaminados pela deposição de resíduos sólidos urbanos no Vazadouro Municipal de Tatuí (SP), a partir de métodos geofísicos (eletrorresistividade e eletromagnético) e de técnicas diretas de investigação, que envolveram a coleta de água subterrânea em poços de monitoramento, análises químicas e físico-químicas periódicas.

\section{CARACTERIZAÇÃO DA ÁREA DE ESTUDO}

A área do Vazadouro de Tatuí está localizada na zona geomorfológica do Médio Tietê, Depressão Periférica Paulista, e caracteriza-se pela ocorrência de colinas amplas e médias com amplitudes inferiores a $100 \mathrm{~m}$, topos aplainados e vertentes com perfis convexos e retilíneos (ROSS \& MOROZ 1997).

O clima é caracterizado como Cwa (Köppen), ou seja, mesotérmico úmido, sem estação seca, com verão quente. Os meses mais quentes são janeiro e fevereiro, enquanto os mais frios são junho e julho. A temperatura média é de $21,6^{\circ} \mathrm{C}$ e a pluviosidade é de $1.230 \mathrm{~mm}^{\text {ano-1 }}{ }^{-1}$. Há chuvas ao longo de todo o ano, mas os meses de abril a agosto são relativamente mais secos. As chuvas se intensificam em setembro atingindo o seu máximo em janeiro (CEPAGRI 2016).

$\mathrm{Na}$ área do lixão afloram rochas carboníferas da Formação Tatuí (Grupo Tubarão), que na região é predominantemente constituída de siltitos, com ocorrência subordinada de camadas de arenitos, calcários, folhelhos, com presença de sílex (IPT 1981). O conjunto possui uma sedimentação bem uniforme e a sua maior espessura na área aflorante é da ordem de $130 \mathrm{~m}$, no sul do estado de São Paulo, diminuindo para nordeste e para norte, em direção à borda da bacia (IPT 1981). O contato inferior ocorre com as rochas do Subgrupo Itararé, a menos de $1 \mathrm{~km}$ a leste do Vazadouro, abaixo da cota $550 \mathrm{msnm}$.

Segundo GIMENEZ (1996), na região de estudo, a porção inferior da Formação Tatuí é formada por siltitos acinzentados a verde claro, com estruturas lenticulares preenchidas por areia fina de coloração esbranquiçada. São frequentes as intercalações de arenitos finos e maciços, assim como conglomerados angulosos a arredondados de quartzo e sílex com até $5 \mathrm{~cm}$ de diâmetro. $\mathrm{O}$ topo da seção é caracterizado por folhelhos avermelhados plano-paralelos, com intercalações de calcário. Atribui-se à Formação Tatuí um ambiente de sedimentação em bacia aquosa de baixa energia, possivelmente marinha. Estes sedimentos representam um episódio de transgressão marinha pós-glacial ocorrido na bacia (IPT 1981, DAEE/IG/ IPT/CPRM 2005).

O Sistema Aquífero Tubarão é uma unidade hidrogeológica muito heterogênea, territorialmente extensa e, em geral, apresenta uma grande variação em sua produtividade. Vários autores (DAEE 1981, IG/CETESB/DAEE 1997, DAEE/IG/IPT/ CPRM 2005) obtiveram valores de vazão média de 3,00 a $30,00 \mathrm{~m}^{3} \mathrm{~h}^{-1}$, capacidade específica entre 0,005 e $8,50 \mathrm{~m}^{3} \mathrm{~h}^{-1} \mathrm{~m}^{-1}$ e transmissividade entre 0,3 e $200 \mathrm{~m}^{2} \mathrm{dia}^{-1}$. A permeabilidade aparente apresenta distribuições entre 0,002 a $0,70 \mathrm{~m} \mathrm{dia}^{-1}$ e um coeficiente de armazenamento de 0,0001 a 0,05.

$\mathrm{Na}$ área de estudo, entretanto, a geologia, constituída de termos finos, como argilitos e folhelhos, faz com que esta seja de baixa condutividade hidráulica e apresente fluxos de água subterrânea, sobretudo verticais, bastante reduzidos. O lixão de Tatuí está localizado na área de recarga. O aquífero é do tipo granular, de caráter livre e com corpos bastante heterogêneos, devida à presença de sedimentos variados de origem glacial e lacustre, com retrabalhamento fluvial, constantes interdigitações entre as camadas mais arenosas e de lamitos, ritmitos e siltitos (DAEE 1981, IG/CETESB/DAEE 1997), o que tornam sua produtividade muito limitada e heterogênea.

\section{MATERIAIS E MÉTODOS}

O estudo fez uso de técnicas geofísicas e métodos diretos, incluindo a perfuração de poços de monitoramento, coleta e análise de águas subterrâneas.

Inicialmente foram realizadas inspeções nas áreas do empreendimento e circunvizinhanças, levantando o histórico de uso e ocupação da área, a topografia e geomorfologia, a geologia de superfície e avaliação hidrogeológica e os corpos de água superficial. O estudo prosseguiu, em uma segunda fase, com a aplicação de técnicas de investigações indiretas e diretas. 
No caso das investigações indiretas, estas compreenderam trabalhos de geofísica, incluindo: i) nove sondagens elétricas verticais (SEV), utilizando o resistivímetro TDC-1000/12 da Tectrol em arranjo Schlumberger (TELFORD et al. 1990, OKOLIE et al. 2010), com espaçamento máximo entre os eletrodos de corrente AB de $120 \mathrm{~m}$ (Figura 2), interpretados com o auxílio do software desenvolvido por BASOKUR (1990); ii) caminhamentos eletromagnéticos induzidos (CEM), que investigaram profundidades teóricas de até $6 \mathrm{~m}$ com o equipamento EM31 e até $15 \mathrm{~m}$ com o EM34, ambos da Geonics (GREENHOUSE \& SLAINE 1983, MONIER-WILLIAMS et al. 1990, GREENHOUSE et al. 1998), num total de $7.131 \mathrm{~m}$ lineares (Figuras 3 e 4); estes dados foram interpolados pelo método geoestatístico de krigagem, com o auxílio do software Surfer (GOLDEN SOFTWARE 2016).

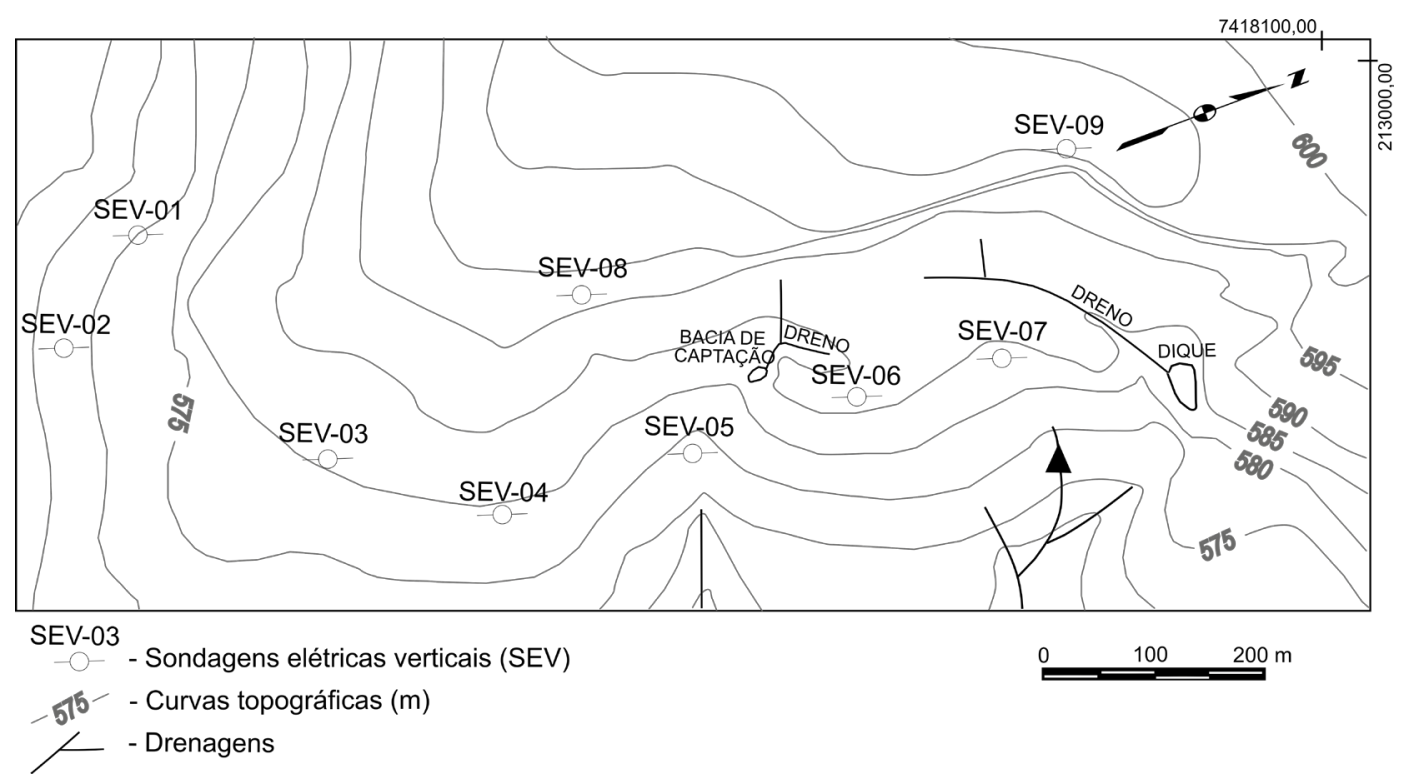

FIGURA 2 - Localização das sondagens elétricas verticais (SEV).

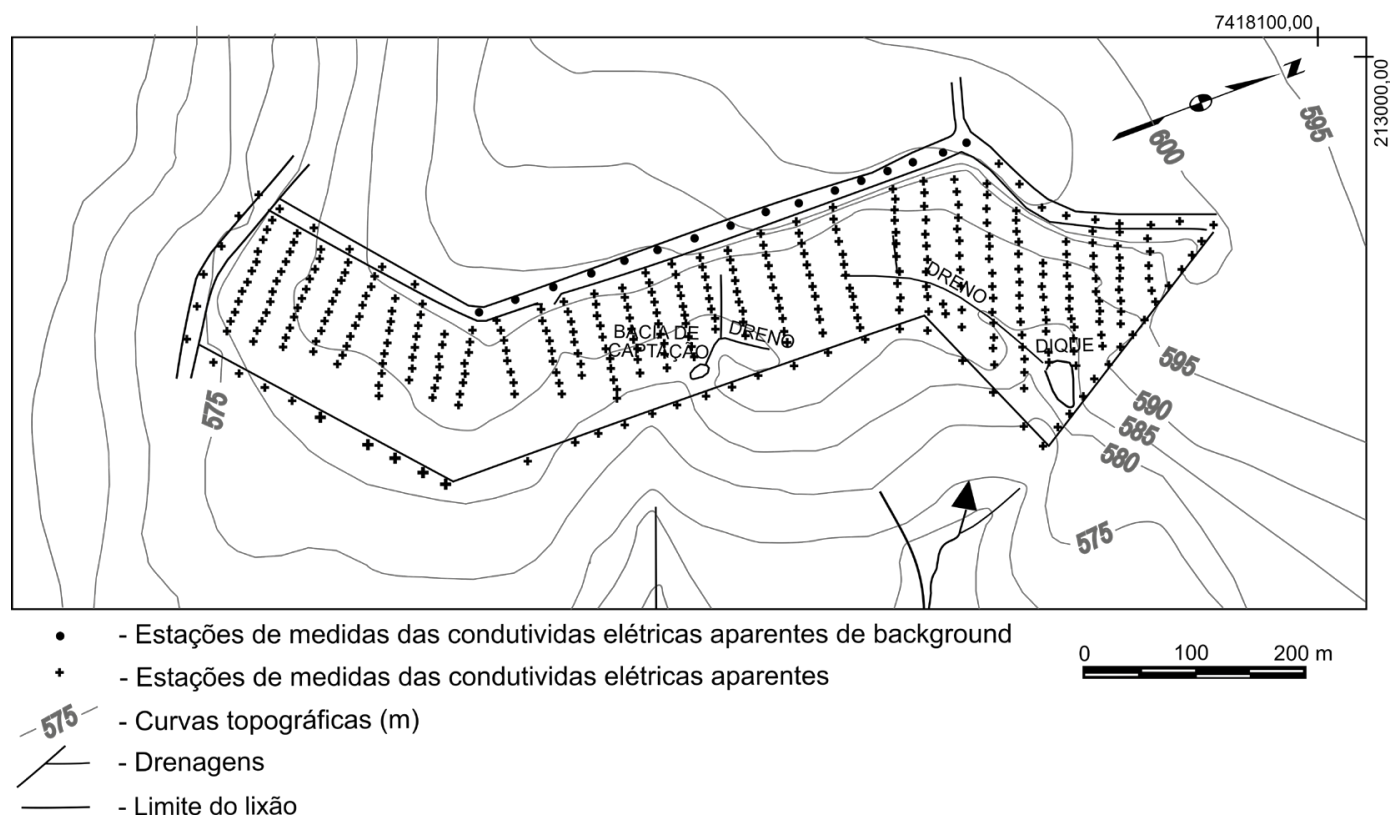

FIGURA 3 - Localização das estações de medidas dos caminhamentos eletromagnéticos com o equipamento EM31. 


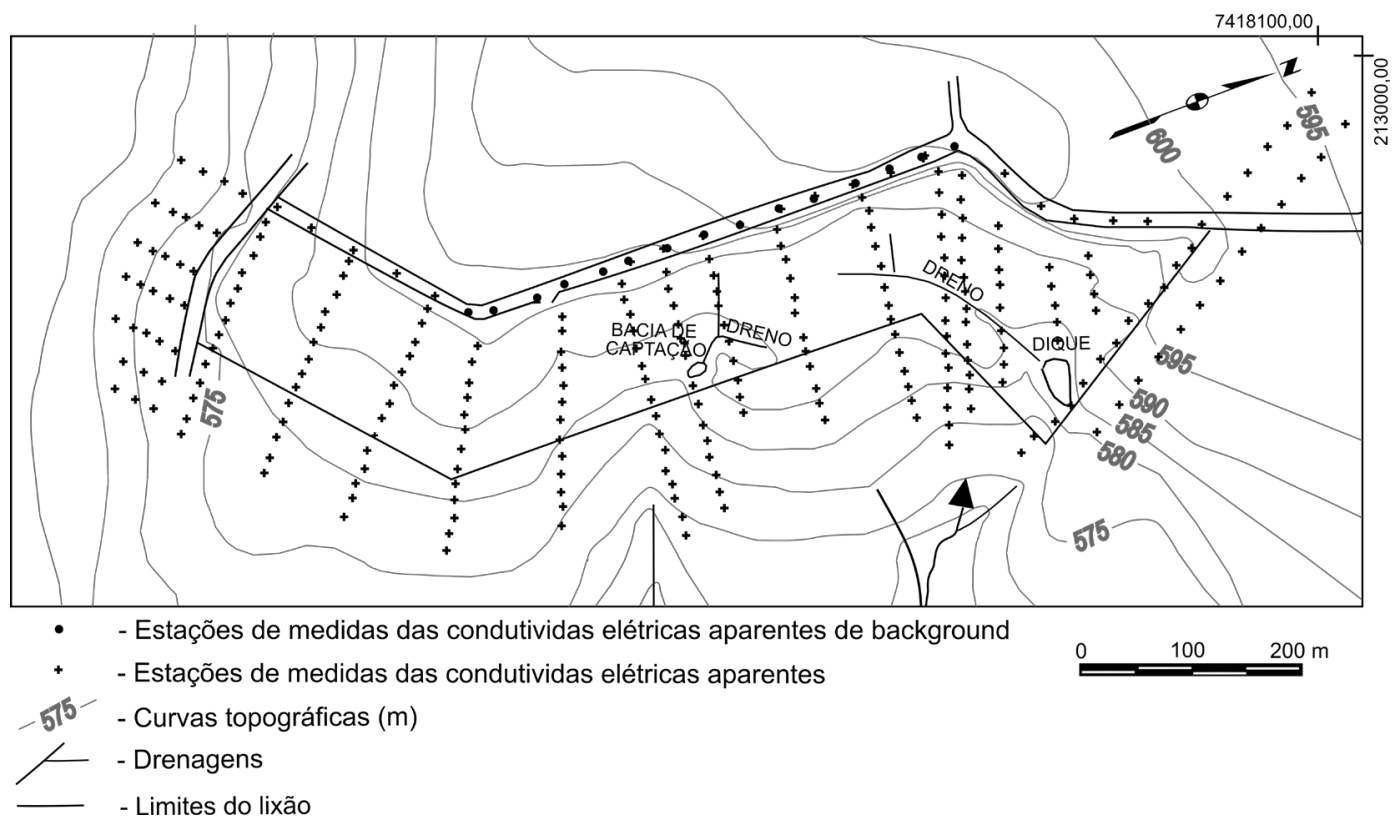

FIGURA 4 - Localização das estações de medidas dos caminhamentos eletromagnéticos com o equipamento EM34.

As investigações diretas consistiram no acesso direto ao aquífero a partir da perfuração de 12 poços de monitoramento, perfurados com $100 \mathrm{~mm}$ de diâmetro, com uso de trado manual e revestidos com tubos e filtro de PVC e areia de pré filtro do tipo pérola. Os níveis da água subterrânea foram monitorados através de medidores elétricos manuais, e amostras de água dos poços de monitoramento e cacimba foram coletadas durante seis campanhas mensais de amostragens no período de julho de 2000 a janeiro de 2001. Foram analisados $\mathrm{Cl}^{-}, \mathrm{NH}_{4}{ }^{+}, \mathrm{NO}_{3}^{-}, \mathrm{NO}_{2}^{-}, \mathrm{SO}_{4}{ }^{2-}$ pelo método de cromatografia iônica, $\mathrm{Ca}^{2+}, \mathrm{Na}^{+}, \mathrm{K}^{+}, \mathrm{Fe}^{2+}, \mathrm{Fe}^{3+}, \mathrm{Mn}^{2+}$, $\mathrm{Al}^{3+}, \mathrm{Mg}^{2+}, \mathrm{Ba}^{2+}, \mathrm{Cd}^{2+}, \mathrm{Cr}^{6+}, \mathrm{Cu}^{2+}, \mathrm{Hg}^{2+}, \mathrm{Mo}^{4+}, \mathrm{Pb}^{2+}$, $\mathrm{Sr}^{2+}, \mathrm{Ti}^{2+}, \mathrm{V}^{3+}, \mathrm{Sn}^{2+}, \mathrm{Zn}^{2+}$ e $\mathrm{Zr}^{2+}$, por ICP-MS. Alcalinidade, $\mathrm{N}$ (amoniacal) e $\mathrm{N}$ (Kjedahl), foram determinados por titulação potenciométrica. No campo, foram medidos com equipamento portátil a condutividade elétrica e por extrapolação destes resultados, calculou-se os sólidos totais dissolvidos (STD). As coletas foram feitas com o uso de garrafas amostradoras de PVC descartáveis (bailer com válvula de pé). Em seguida as amostras de água foram filtradas (filtro acetato celulose $0,45 \mathrm{~mm}$ ) e as alíquotas para análise de cátions foram acidificadas $(\mathrm{pH}<2)$. Ambas as alíquotas, de cátions e ânions, foram refrigeradas e analisadas no laboratório Conceito Tecnologia Química, segundo as metodologias do APHA (1999).

\section{RESULTADOS OBTIDOS}

Os dados geofísicos foram integrados com aqueles obtidos na investigação direta, a partir do acompanhamento dos níveis e da qualidade das águas subterrâneas nos poços de monitoramento, permitindo dar maior consistência à interpretação de resultados de campo. Os itens a seguir detalham os resultados de ambos os métodos.

\subsection{Investigações geofísicas}

\subsubsection{Sondagens elétricas verticais}

As curvas das SEV mostraram uma morfologia bastante homogênea em toda a área, permitindo correlacionar as seguintes camadas geoelétricas: zona não saturada, zona saturada e o aquitarde, que representa a base do aquífero (Tabela 1). Este último, bastante evidente, caracteriza-se por resistividades muito superiores às demais $\left(>10.000 \Omega \mathrm{m}^{-1}\right)$ e ampla distribuição espacial e continuidade lateral. As SEV 5 e 8 apresentaram resultados desta última camada geoelétrica com valores significativamente menores ao restante (ao redor de $250-300 \Omega \mathrm{m}^{-1}$ ). No campo, não houve nenhum indício geológico que explicasse tal comportamento. Entretanto, os outros resultados são condizentes com os observados nas descrições litológicas e de níveis de água dos poços de monitoramento perfurados na área. 


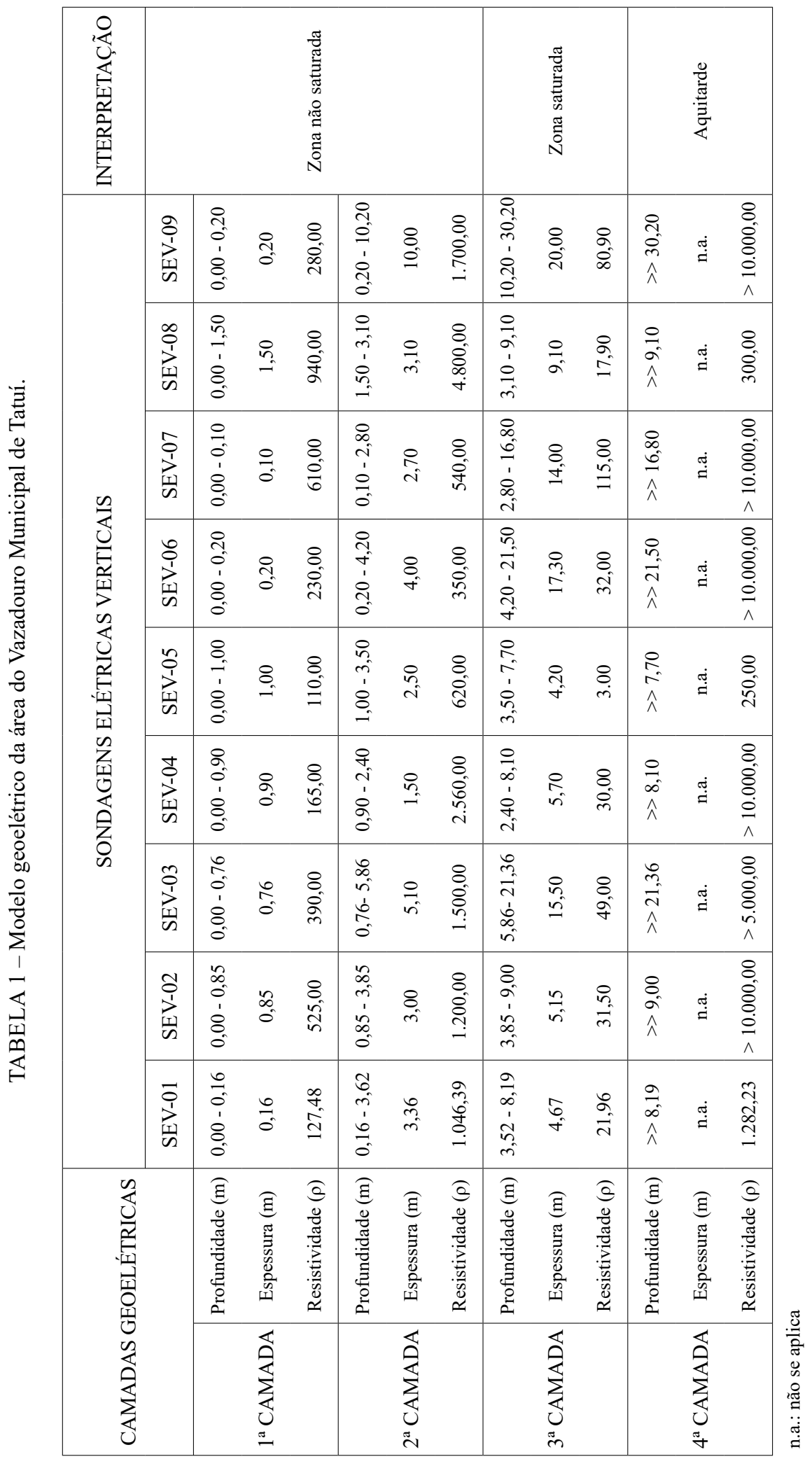




\subsubsection{Caminhamentos eletromagnéticos}

Inicialmente foram realizados os CEM para caracterizar os valores das condutividades elétricas aparentes $\left(\mathrm{CE}_{\mathrm{ap}}\right)$ da área não impactada pelo lixão, com dois equipamentos (EM31 e EM34) (HUTCHINSON \& BARTA 2000). As $\mathrm{CE}_{\text {ap }}$ até
20 e $40 \mathrm{~S} \mathrm{~m}^{-1}$ foram interpretadas como valores de background para as investigações até $6 \mathrm{~m}$ com o EM31 (Figuras 5 e 6) e até 15 m com o EM34 (Figuras 7 e 8), respectivamente. Acima destes valores as condutividades foram consideradas anômalas para a área, ou seja, com impacto do lixo ou do próprio resíduo sólido enterrado.

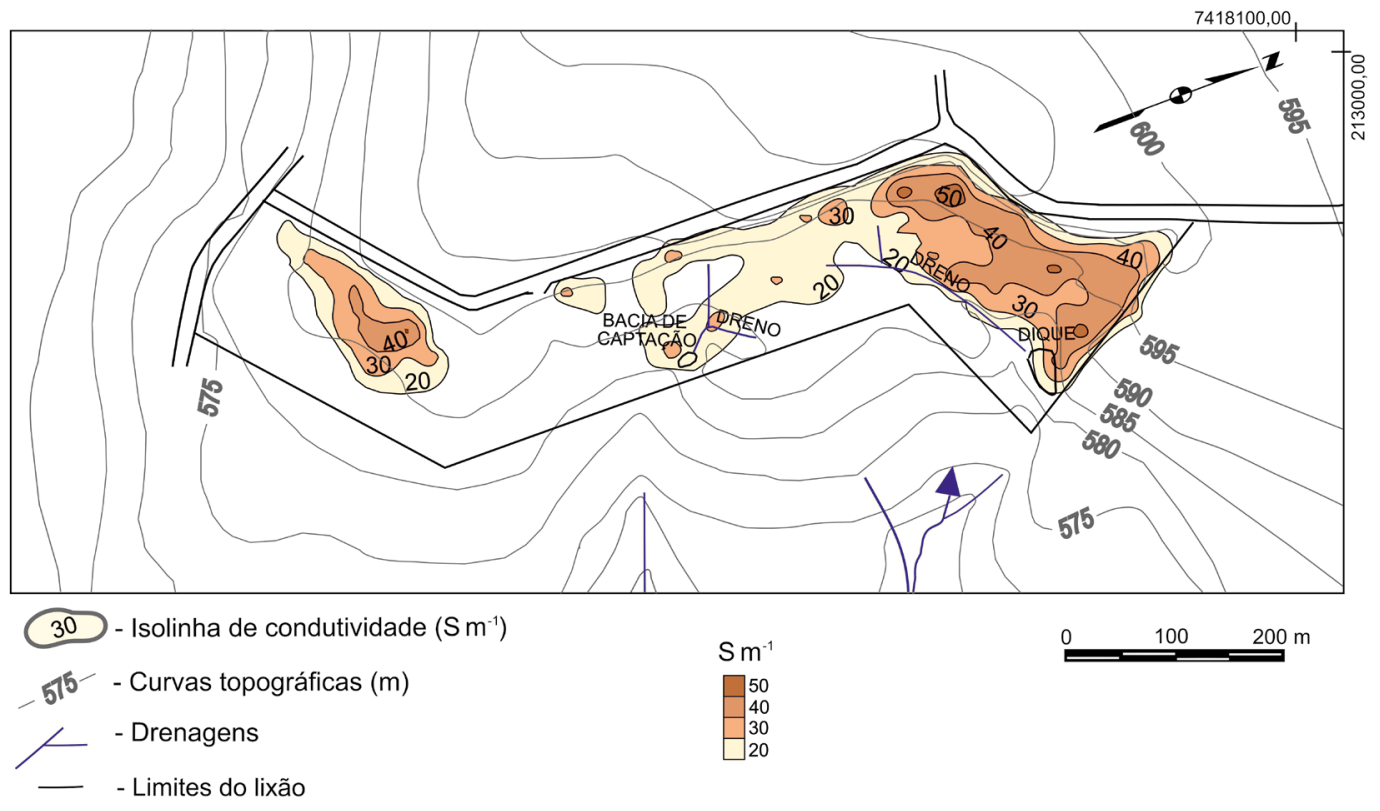

FIGURA 5 - Anomalias eletromagnéticas $\left(>20 \mathrm{~S} \mathrm{~m}^{-1}\right)$ obtidas com o EM31 até $3 \mathrm{~m}$ de profundidade.

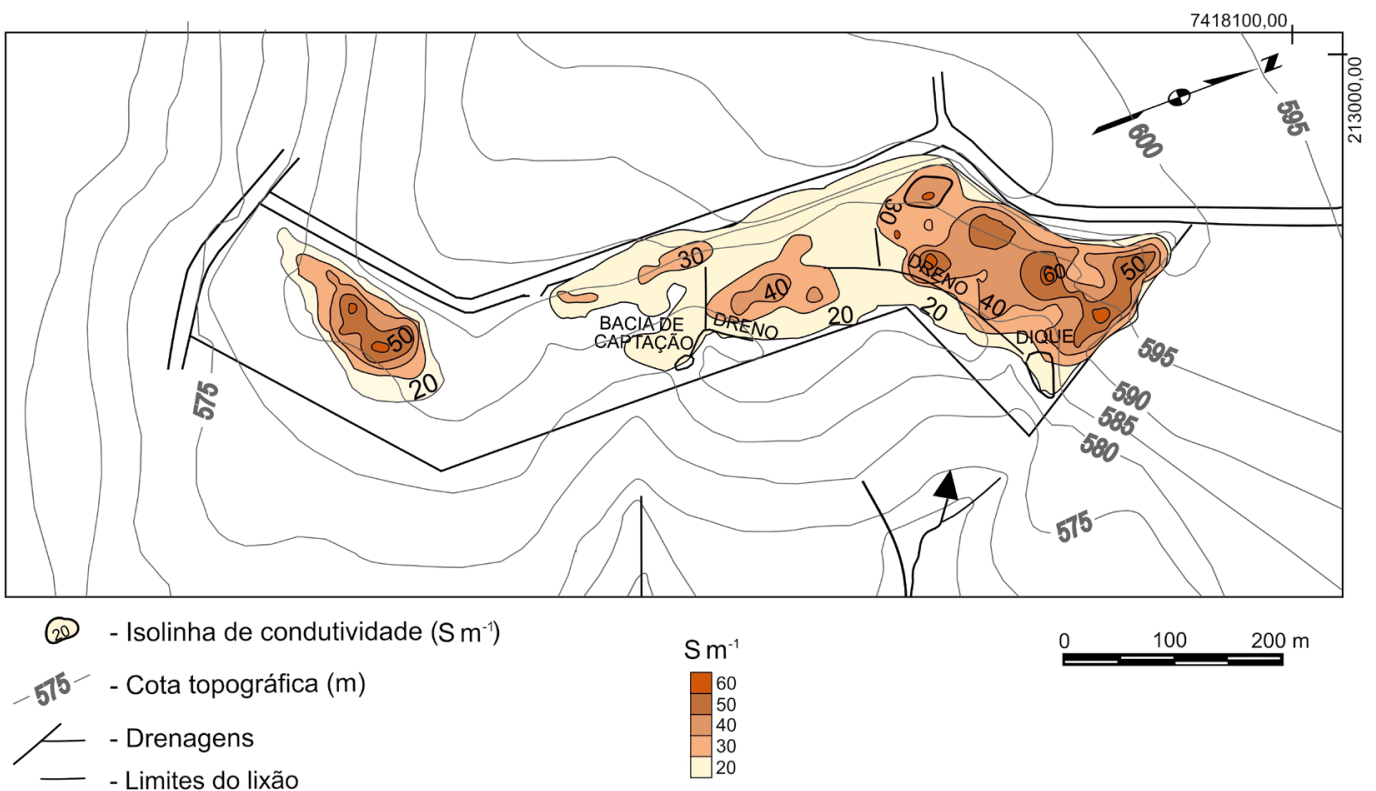

FIGURA 6 - Anomalias eletromagnéticas $\left(>20 \mathrm{~S} \mathrm{~m}^{-1}\right)$ obtidas com o EM31 até $6 \mathrm{~m}$ de profundidade. 


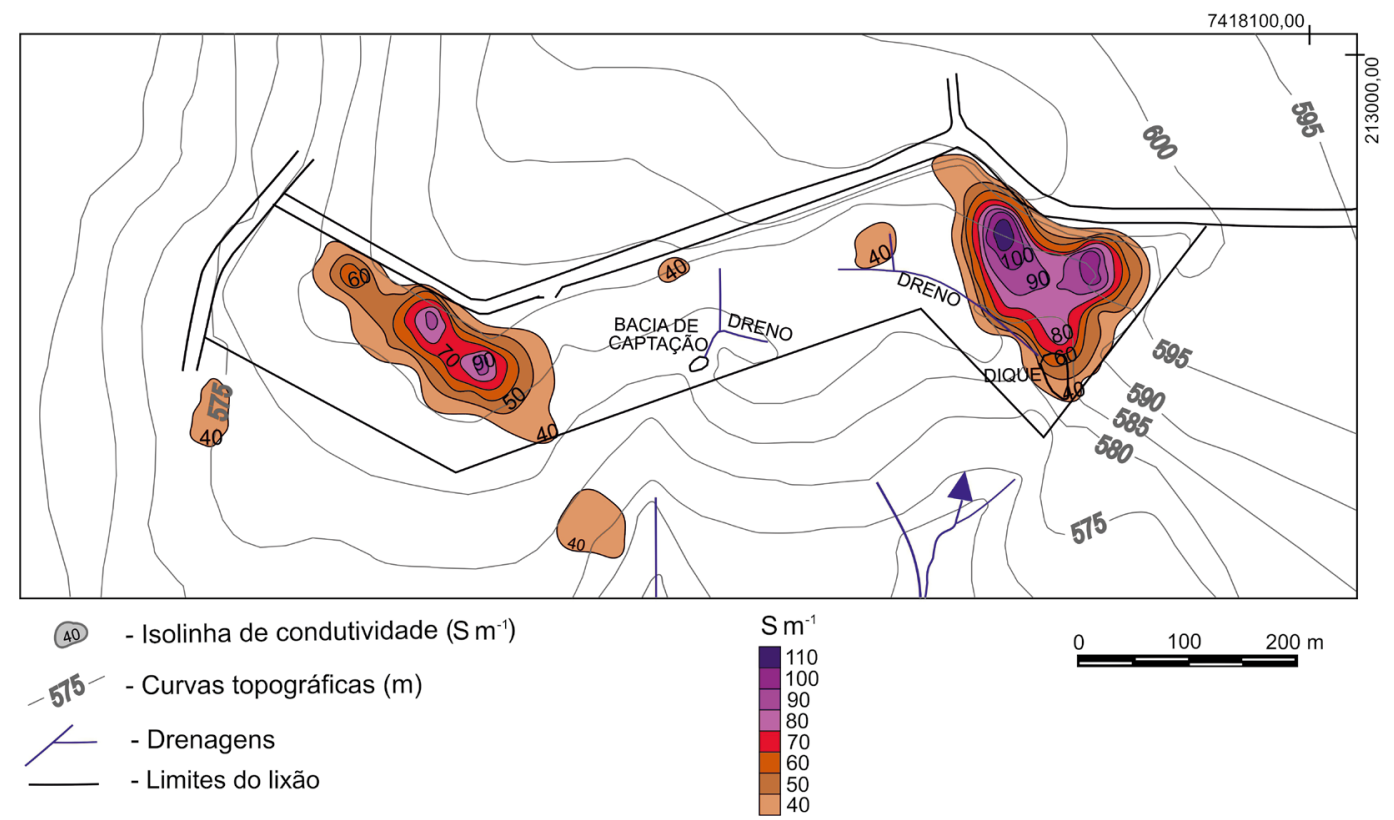

FIGURA 7 - Anomalias eletromagnéticas $\left(>40 \mathrm{~S} \mathrm{~m}^{-1}\right)$ obtidas com o EM34 até $8 \mathrm{~m}$ de profundidade.

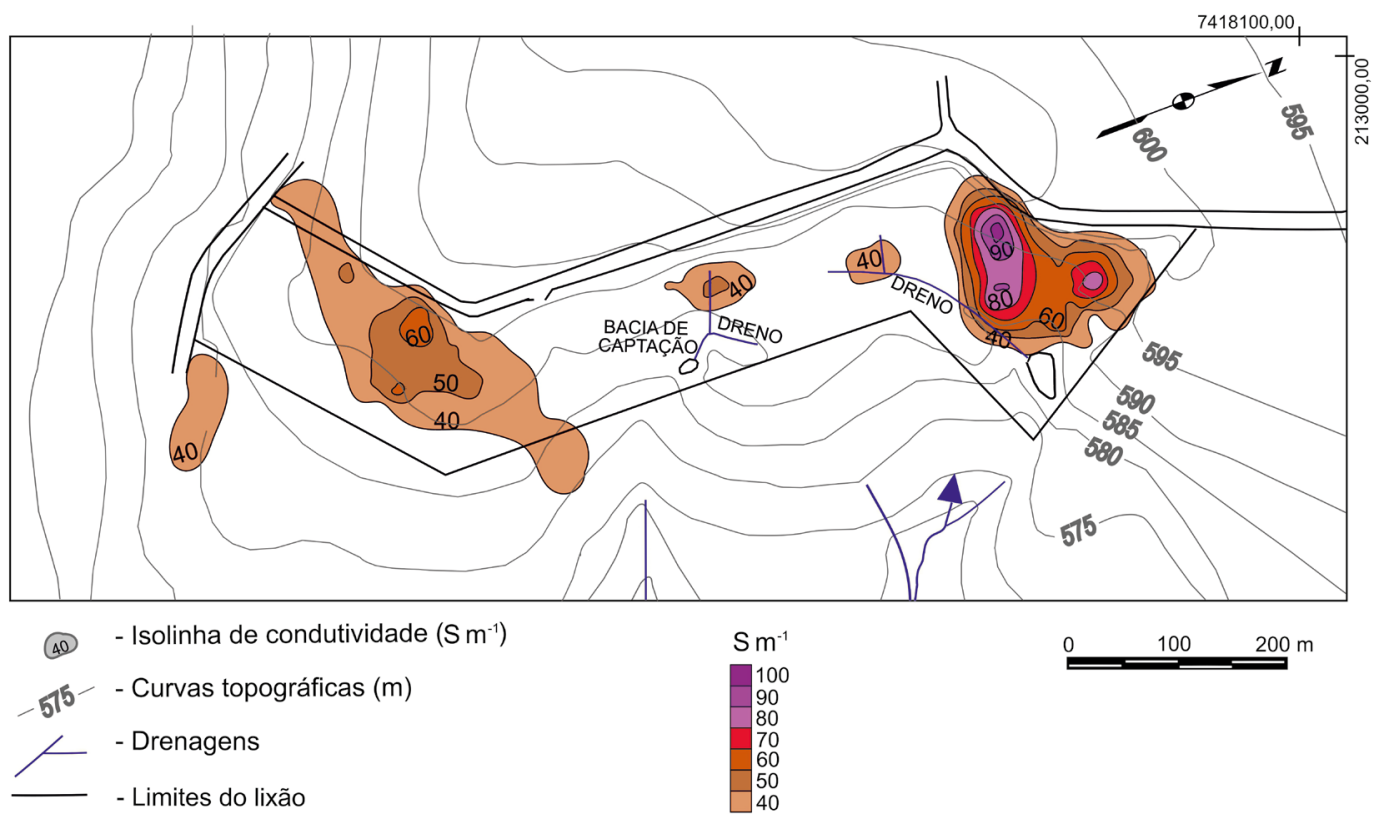

FIGURA 8 - Anomalias eletromagnéticas $\left(>40 \mathrm{~S} \mathrm{~m}^{-1}\right)$ obtidas com o EM34 até $15 \mathrm{~m}$ de profundidade.

Como EM31 tem pequena capacidade de penetração no solo, este serviu para identificar o local da deposição do lixo, pois há um grande contraste elétrico entre o solo original e o resíduo sólido em pouca profundidade, colocado em cavas abertas na zona não saturada (Figuras 5 e 6). As- sim, a linha de $\mathrm{CE}_{\mathrm{ap}}>20 \mathrm{~S} \mathrm{~m}^{-1}$ mostra aproximadamente o contorno do resíduo sólido enterrado na área (Figura 5). Tal resultado é concordante com o observado, caminhando-se no local do Vazadouro. Já o EM34 mostra resultados em profundidades maiores que $8 \mathrm{~m}$, dentro da zona saturada. 
Há dois focos de maiores valores $\left(>40 \mathrm{~S} \mathrm{~m}^{-1}\right)$, um na porção norte do lixão e outro na sul (Figura 7), e a partir destes observa-se uma dispersão de valores de condutividade elétrica, que poderiam ser relacionados às águas subterrâneas impactadas. É também notório que os valores do EM34 em maior profundidade (até $15 \mathrm{~m}$ ) dão ideia de maior dispersão (Figura 8) e são concordantes com o fluxo de água subterrânea (Figura 9).

A avaliação dos quatro resultados de CEM sugere a posição do lixo e também do impacto esperado nas águas subterrâneas, entretanto, não foram observados indícios de contaminação do aquífero fora da área de deposição dos resíduos.

\subsection{Hidrogeologia local}

Localmente, a área apresenta um sistema hidrogeológico composto por duas unidades. A primeira é formada por sedimentos argilo-siltosos compactos, impenetráveis ao trado manual, que caracterizam o aquitarde presente em toda a área de estudo, como comprovam todas as SEV, ademais das descrições litológicas dos 12 poços de monitoramento. Este aquitarde é a base de um aquífero livre e raso, com espessura saturada média em torno de $8 \mathrm{~m}$, constituído por sedimentos predominantemente siltosos, pouco a muito argilosos, intercalados com porções silto-arenosas finas.

A recarga do aquífero está associada ao excedente hídrico, condicionada pelo regime pluviométrico. Durante o estudo, nos meses de setembro, novembro e dezembro de 2000 e fevereiro e março de 2001 (Figura 10), houve indicação de excedentes hídricos, que, potencialmente poderiam ser convertidos em recargas ao aquífero, em um total de $327 \mathrm{~mm} \mathrm{ano}^{-1}$. Entretanto, devida à baixa permeabilidade vertical da zona não saturada, acredita-se que somente uma pequena fração deste valor realmente tenha atingido o aquífero. Tais cálculos foram efetuados com métodos clássicos de balanço hídrico de solo (THORNTHWAITE \& MATHER 1955), a partir dos dados da estação meteorológica de Sorocaba (A713; OMM 86907, latitude $-23.42^{\circ}$ e longitude $\left.-47.58^{\circ}\right)$.

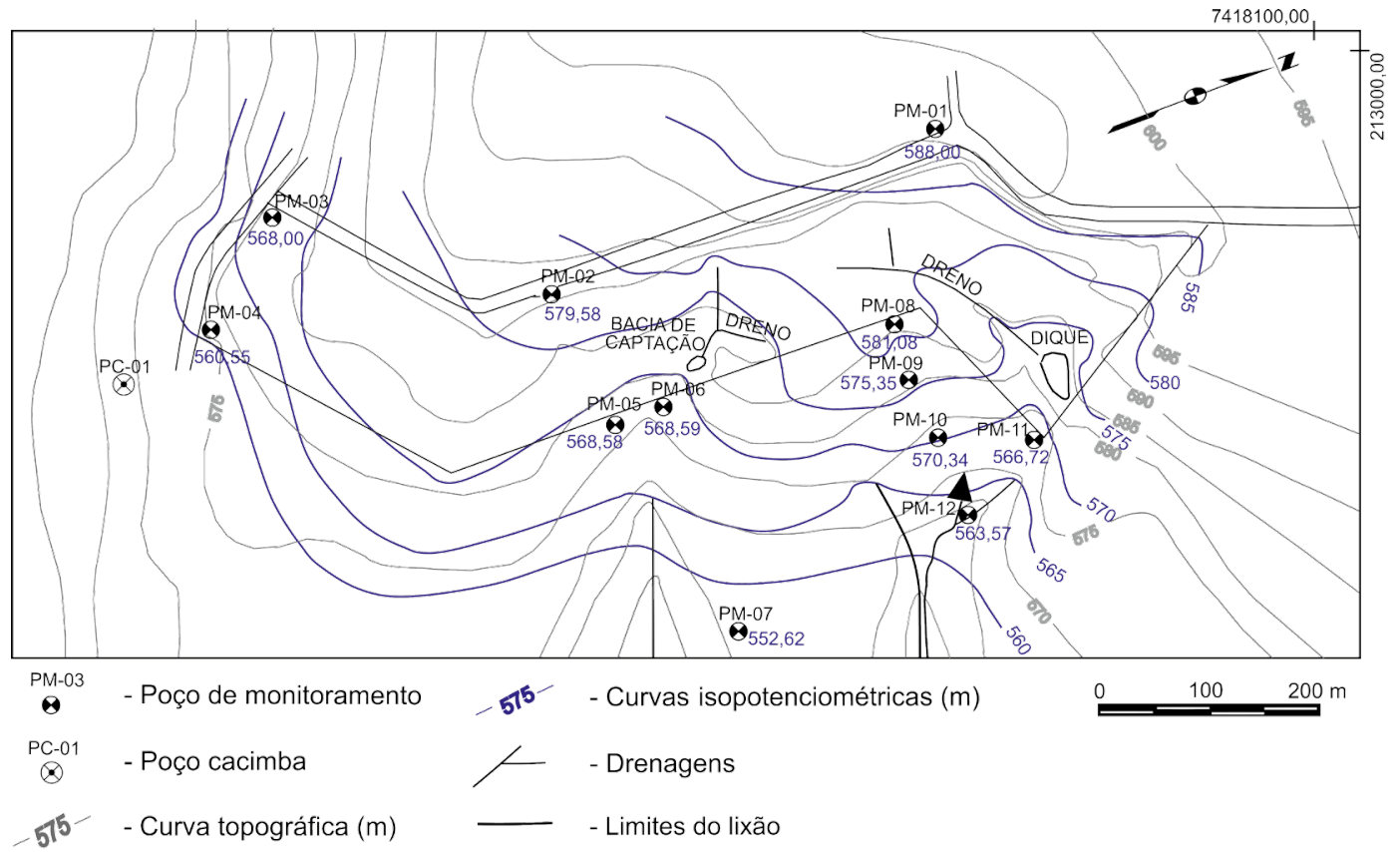

FIGURA 9 - Nível potenciométrico do aquífero na área de estudo em agosto de 2000. 


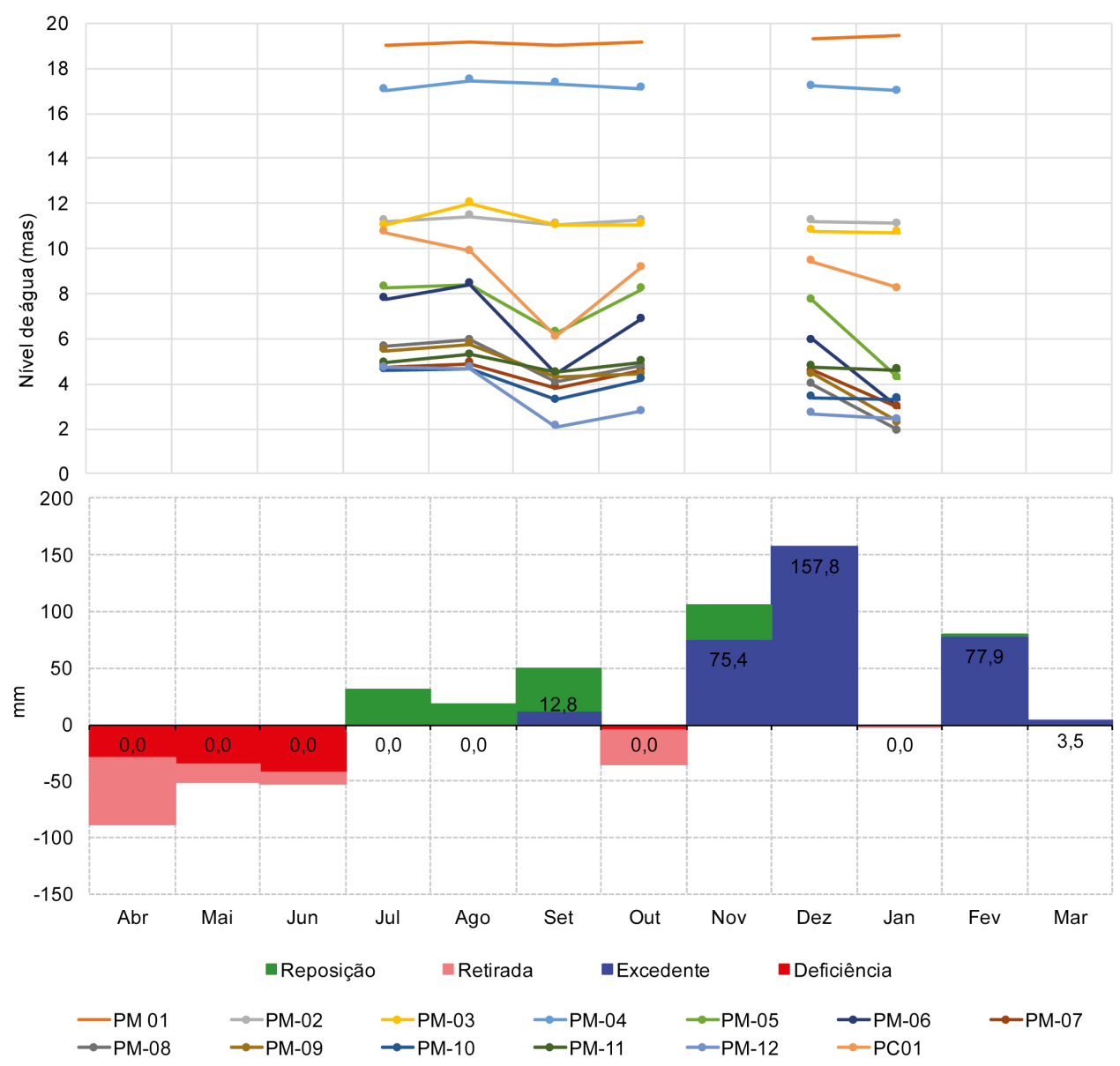

FIGURA 10 - Balanço hídrico no município de Tatuí no ano hidrológico de abril de 2000 até março de 2001, com excedentes hídricos ( $\mathrm{mm} \mathrm{mês}^{-1}$ ) em azul, totalizando $327 \mathrm{~mm}$ ano ${ }^{-1} \mathrm{e}$ variação dos níveis de água nos poços de monitoramento (metros abaixo da superfície $=$ mas).

As observações dos níveis da água nos poços de monitoramento durante o período de estudos mostraram que há uma pequena variação sazonal. Nitidamente, pode-se distinguir três comportamentos na área: i) poços topograficamente mais elevados, com níveis de água $>10 \mathrm{~m}$ (PM-01, PM-02, PM-03, PM-04); ii) poços na meia encosta (10 m - 5 m) (PC-01, PM-04, PM-06, PM-10) e iii) poços nas porções mais baixas $(5 \mathrm{~m}-2 \mathrm{~m})(\mathrm{PM}-07$, PM-10, PM-12).

$\mathrm{O}$ primeiro grupo (i) não apresenta quase nenhuma variação do nível ao longo do ano. Com um pouco mais de variação (sobretudo na campanha de setembro de 2000), há os poços das porções mais rasas (iii). Já os poços da meia encosta são os de maior variação (até $3 \mathrm{~m}$ ao longo do ano). Uma explicação para estes comportamentos relaciona-se à baixa permeabilidade vertical das rochas, impondo uma baixa infiltração (a despeito do elevado excedente hídrico), que explicaria o grupo (i). Como o lixo enterrado aumenta a permeabilidade vertical, os poços de meia encosta e aqueles a jusante do resíduo, seriam os mais influenciados pela recarga. A maior permeabilidade do resíduo sólido e capacidade de armazenamento de água foram também verificadas por outros autores (FREEZE \& CHERRY 1979, GUIGUER 1987). Já para poços em áreas topográficas mais baixas, os níveis das drenagens acabam por atenuar a variação dos níveis de água nos poços, corroborados pela baixa permeabilidade da zona não saturada. Outro fenômeno que se observa é o tempo de resposta dos níveis de água com as chuvas (Figura 10). Os excedentes de setembro, por exemplo, começam a refletir nos níveis em outubro. 
Surgências de chorume são comuns em várias partes nas áreas com resíduo, principalmente na época das chuvas. O chorume é captado em valetas improvisadas, e daí segue para o dique e bacia de captação escavados no solo e sem impermeabilização na base.

Quanto ao PM-11, este está situado imediatamente a jusante de um dos diques de captação de águas superficiais percoladas no lixão. Este dique encontra-se com água durante todo o ano, restringindo assim as variações dos níveis da água de toda a área.

Assim, a água que infiltra em toda a extensão aflorante do aquífero escoa preferencialmente no sentido NW-SE, vindo a descarregar nas áreas alagadiças a leste, que representam a área topograficamente mais baixa do empreendimento. Entretanto, como o divisor de água subterrânea atravessa o sul do lixão, parte destas águas tem como descarga a drenagem a sudoeste da área (Figura 9). A pouca variação dos níveis de água no aquífero não muda significativamente as direções de fluxo das águas subterrâneas ao longo do ano.

\subsection{Qualidade da água subterrânea}

\subsubsection{Variações das condutividades elétricas}

As condutividades elétricas (CE) das amostras dos poços de monitoramento variaram de 12 a $1.929 \mu \mathrm{S} \mathrm{cm}^{-1}$. A CE tem relação direta com a contaminação, assim como o cloreto, o sódio e alguns outros íons maiores (Tabela 2). Os poços PM-01 e PM-02, localizados a montante do lixão, são claramente não contaminados e usados como referência como águas não impactadas; assim como os poços PM-05 e PM-07 também foram considerados não contaminados pelos seus resultados químicos (Tabela 2). Já os poços restantes (exceto PC-01) foram assumidos como contaminados. Os valores de CE maiores que $100 \mu \mathrm{S} \mathrm{cm}^{-1}$ podem ser usados como indicativos para separar os dois grupos de poços, assim como os valores de $10 \mathrm{mg} \mathrm{L}^{-1}$ de cloreto.

As CE variaram em função da recarga do aquífero, indicando que a percolação da água através do resíduo e a infiltração do chorume no aquífero impactam a água subterrânea, incrementando os valores até $1.929 \mu \mathrm{S} \mathrm{cm}^{-1}$, em contraste com valores naturais de $<100 \mu \mathrm{S} \mathrm{cm}^{-1}$. Existe um aumento dos valores de CE a partir de setembro, quando inicia-se o período com excedente hídrico, embora a variação não seja homogênea em todos os poços. Os poços considerados não influenciados pelo lixo (PM-01, PM-02, PM-04, PM-05, PM-07) tiveram pouca variação positiva nas concentrações de cloreto e mesmo de CE. Já os poços impactados pelo lixo (PM-03, PM-09, PM-10, PM-11, PM-12) apresentaram aumento claro para a CE e para o cloreto, após o início das recargas do aquífero em setembro de 2000. O PM-06 e o PM-08 embora também impactados pelo lixão, apresentaram comportamentos distintos do restante do grupo, com redução das concentrações de cloreto e de CE com as chuvas (Figura 11). O PM-11 apresentou a CE mais alta $\left(1.650\right.$ a $\left.1.929 \mu \mathrm{S} \mathrm{cm}^{-1}\right)$ de toda a área, havendo um pequeno aumento com a chegada das chuvas. Isto deveu-se à proximidade deste poço ao dique com chorume, que possuía uma CE de $2.000 \mu \mathrm{S} \mathrm{cm}^{-1}$ ao longo de todo o tempo do estudo.

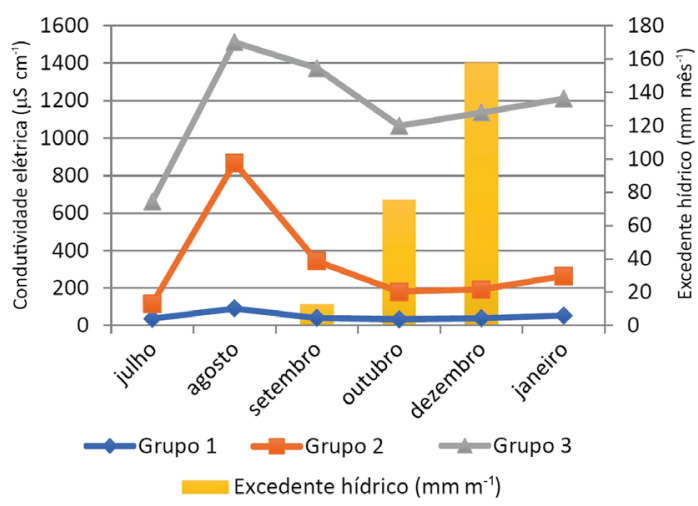

FIGURA 11 - Variação dos valores de condutividade elétrica com o tempo e o excedente hídrico, separados em Grupo 1: poços não impactados pelo lixão (montante das áreas de lixo) [PM-01, 2, 4, 5, 7]; Grupo 2: poços impactados (jusante das áreas de lixo), com redução nos valores com as chuvas [PM-06, 8]; Grupo 3: poços impactados (jusante das áreas de lixo), com incremento nos valores [PM-03, 9, 10, 11, 12].

Os mapas de potenciometria e de isovalores de CE indicam que a pluma de contaminação atingiu as águas subterrâneas (Figura 12 e 13), mas manteve-se dentro dos limites geográficos do lixão ou muito próximo a ele (até $100 \mathrm{~m}$ ). Tal resultado é também corroborado tanto pelos CE rasos, como pelo EM31, que na figura 5 indica a posição do resíduo enterrado, enquanto na figura 6 , o impacto na zona saturada rasa. 
TABELA 2 - Resultados analíticos das águas subterrâneas das seis campanhas de monitoramento ( $1^{\mathrm{a}} \mathrm{e} 2^{\mathrm{a}}$ campanhas).

\begin{tabular}{|c|c|c|c|c|c|c|c|c|c|c|c|c|c|c|c|}
\hline $\begin{array}{l}\text { Parâmetro } \\
\text { (unidade) }\end{array}$ & $\begin{array}{c}\text { PM- } \\
01\end{array}$ & $\begin{array}{c}\text { PM- } \\
02\end{array}$ & $\begin{array}{l}\text { PM- } \\
03\end{array}$ & $\begin{array}{c}\text { PM- } \\
04\end{array}$ & $\begin{array}{l}\text { PM- } \\
05\end{array}$ & $\begin{array}{l}\text { PM- } \\
06\end{array}$ & $\begin{array}{c}\text { PM- } \\
07\end{array}$ & $\begin{array}{l}\text { PM- } \\
08\end{array}$ & $\begin{array}{c}\text { PM- } \\
09\end{array}$ & $\begin{array}{c}\text { PM- } \\
10\end{array}$ & $\begin{array}{c}\text { PM- } \\
11\end{array}$ & $\begin{array}{l}\text { PM- } \\
12\end{array}$ & $\begin{array}{c}\text { PC- } \\
01\end{array}$ & $\begin{array}{c}\text { Limite } \\
\text { de } \\
\text { detecção }\end{array}$ & $\begin{array}{l}\text { Padrões } \\
\text { de } \\
\text { qualidade }\end{array}$ \\
\hline \multicolumn{16}{|c|}{$1^{\text {a }}$ Campanha (02 de julho de 2000$)$} \\
\hline $\begin{array}{l}\text { Cond. Elétrica } \\
\qquad\left(\mu \mathrm{S} \mathrm{cm}^{-1}\right)\end{array}$ & 80 & 20 & 630 & 40 & 20 & 60 & 20 & 100 & 60 & 110 & 1.650 & 280 & 18 & n.e. & n.e. \\
\hline $\mathrm{pH}$ & 5,45 & 5,09 & 5,73 & 5,28 & 5,20 & 5,70 & 4,40 & 4,45 & 4,60 & 6,40 & 6,20 & 5,80 & 4,90 & n.e. & n.e. \\
\hline Temp. $\left({ }^{\circ} \mathrm{C}\right)$ & 23,6 & 24,5 & 24,8 & 23,6 & 25,0 & 25,0 & 25,0 & 25,0 & 25,0 & 25,0 & 25,0 & 25,0 & 22,9 & n.e. & n.e. \\
\hline $\mathrm{Cl}^{-}\left(\mathrm{mg} \mathrm{L}^{-1}\right)$ & 0,80 & 0,32 & 139,00 & 3,00 & 0,70 & 27,5 & 0,90 & 240,00 & 12,70 & 18,3 & 47,00 & 47,00 & 0,50 & $<0,50$ & 250 \\
\hline $\mathrm{SO}_{4}^{-2}\left(\mathrm{mg} \mathrm{L}^{-1}\right)$ & 1,10 & 1,20 & 2,20 & 0,50 & 3,80 & 0,50 & 9,30 & 14,00 & 2,80 & 0,50 & 1,40 & 1,40 & 0,50 & $<0,50$ & 400 \\
\hline $\mathrm{NH}_{4}^{+}\left(\mathrm{mg} \mathrm{L}^{-1}\right)$ & 0,46 & 0,11 & 1,90 & 0,44 & 0,62 & 1,60 & 1,22 & 5,00 & 0,06 & 1,34 & 0,05 & 0,05 & 0,40 & $<0,01$ & n.e. \\
\hline $\mathrm{NO}_{3}{ }^{-}\left(\mathrm{mg} \mathrm{L}^{-1}\right)\left(^{*}\right)$ & n.d. & n.d. & n.d. & n.d. & n.d. & 0,80 & n.d. & n.d. & 1,40 & n.d. & 4,40 & 4,40 & n.d. & $<0,50$ & 10 \\
\hline $\mathrm{NO}_{2}^{-}\left(\mathrm{mg} \mathrm{L}^{-1}\right)$ & n.d. & n.d. & n.d. & n.d. & n.d. & n.d. & n.d. & n.d. & n.d. & n.d. & n.d. & n.d. & n.d. & $<0,50$ & n.e. \\
\hline \multicolumn{16}{|c|}{$2^{\text {a }}$ Campanha (08 de agosto de 2000$)$} \\
\hline $\begin{array}{l}\text { Cond. } \\
\text { Elétrica }\left(\mu \mathrm{S} \mathrm{cm}^{-1}\right)\end{array}$ & 161 & 77 & 656 & 70 & 81 & 190 & 67 & 1.363 & 320 & 107 & 1.805 & 333 & 70 & n.e. & n.e. \\
\hline $\mathrm{pH}$ & 6,07 & 5,18 & 5,85 & 5,41 & 4,96 & 5,13 & 5,02 & 4,51 & 5,03 & 5,35 & 5,33 & 5,37 & 5,41 & n.e. & n.e. \\
\hline Temp. $\left({ }^{\circ} \mathrm{C}\right)$ & 24,1 & 23,2 & 22,7 & 23,6 & 23,3 & 23,6 & 23,3 & 23,4 & 23,0 & 22,4 & 21,6 & 21,7 & 23,6 & n.e. & n.e. \\
\hline $\begin{array}{l}\text { Alcalinidade } \\
\left(\mathrm{mg} \mathrm{L}^{-1}\right)\end{array}$ & 39 & 19 & 64 & 28 & 19 & 14 & 19 & 17 & 21 & 23 & 44 & 19 & 27 & n.e. & n.e. \\
\hline $\mathrm{Na}^{+}\left(\mathrm{mg} \mathrm{L}^{-1}\right)$ & 3,00 & 1,70 & 51,00 & 3,50 & 2,10 & 6,90 & 2,00 & 172,00 & 5,10 & 6,50 & 223,00 & n.d. & 1,50 & $<0,05$ & n.e. \\
\hline $\mathrm{Cl}^{-}\left(\mathrm{mg} \mathrm{L}^{-1}\right)$ & 0,48 & 0,36 & 102,00 & 4,20 & 0,35 & 31,00 & 0,78 & 385,00 & 8,40 & 12,00 & 534,00 & 54,00 & 0,05 & $<0,50$ & 250 \\
\hline $\mathrm{K}^{+}\left(\mathrm{mg} \mathrm{L}^{-1}\right)$ & 1,30 & 0,18 & 12,00 & 1,50 & 0,78 & 1,10 & 0,72 & 5,70 & 0,88 & 2,10 & 9,80 & 3,10 & 0,76 & $<0,50$ & n.e. \\
\hline $\mathrm{Ca}^{2+}\left(\mathrm{mg} \mathrm{L}^{-1}\right)$ & 0,93 & 0,70 & 8,01 & 0,75 & 0,96 & 1,77 & 0,43 & 29,10 & 1,59 & 1,48 & 27,84 & 6,92 & 0,61 & $<0,05$ & n.e. \\
\hline $\mathrm{Mg}^{2+}\left(\mathrm{mg} \mathrm{L}^{-1}\right)$ & 0,61 & 0,16 & 8,50 & 1,20 & 0,78 & 3,10 & 0,57 & 19,00 & 0,87 & 1,00 & 25,00 & 5,70 & 0,56 & $<0,05$ & n.e. \\
\hline $\mathrm{SO}_{4}{ }^{2-}\left(\mathrm{mg} \mathrm{L}^{-1}\right)$ & 1,20 & n.d. & 1,46 & 0,50 & n.d. & 0,72 & $<0,50$ & 28,00 & 0,50 & 0,64 & 10,00 & 0,86 & n.d. & $<0,50$ & 400 \\
\hline $\mathrm{NH}_{4}^{+}\left(\mathrm{mg} \mathrm{L}^{-1}\right)$ & 0,85 & 0,01 & 6,40 & 0,09 & 0,01 & 0,13 & 0,01 & 88,00 & 0,01 & 0,61 & 26,00 & 0,01 & 0,01 & $<0,01$ & n.e. \\
\hline $\mathrm{NO}_{3}^{-}\left(\mathrm{mg} \mathrm{L}^{-1}\right)\left(^{*}\right)$ & n.d. & n.d. & n.d. & 0,50 & n.d. & n.d. & 0,50 & 22,00 & 0,62 & n.d. & 0,94 & 6,90 & n.d. & $<0,50$ & 10 \\
\hline $\mathrm{NO}_{2}^{-}\left(\mathrm{mg} \mathrm{L}^{-1}\right)$ & n.d. & n.d. & n.d. & n.d. & n.d. & n.d. & n.d. & n.d. & n.d. & n.d. & n.d. & n.d. & n.d. & $<0,50$ & n.e. \\
\hline $\begin{array}{l}\text { N Kjeldahl } \\
\left(\mathrm{mg} \mathrm{L}^{-1}\right)\end{array}$ & n.d. & n.d. & n.d. & n.d. & n.d. & n.d. & n.d. & n.d. & n.d. & n.d. & n.d. & n.d. & n.d. & $<0,01$ & n.e. \\
\hline $\begin{array}{l}\text { N Amoniacal } \\
\left(\mathrm{mg} \mathrm{L}^{-1}\right)\end{array}$ & n.a. & n.a. & n.a. & n.a. & n.a. & n.a. & n.a. & n.a. & n.a. & n.a. & n.a. & n.a. & n.a. & $<0,02$ & n.e. \\
\hline $\mathrm{Fe}^{2+}\left(\mathrm{mg} \mathrm{L}^{-1}\right)$ & 0,19 & n.d. & 3,9 & n.d. & n.d. & n.d. & n.d. & 0,39 & 0,06 & n.d. & n.d. & n.d. & n.d. & $<0,05$ & n.e. \\
\hline $\mathrm{Fe}$ Total $\left(\mathrm{mg} \mathrm{L}^{-1}\right)$ & 5,70 & 37,00 & 953,00 & 175,00 & 1,30 & 0,88 & 5,70 & 2,40 & 1,50 & 19,00 & 24,00 & 9,20 & 1,50 & $<0,05$ & 0,3 \\
\hline $\mathrm{Mn}^{2+}\left(\mathrm{mg} \mathrm{L}^{-1}\right)$ & 0,91 & n.d. & 1,00 & 0,15 & 0,19 & 0,18 & n.d. & 9,80 & 0,12 & 0,13 & 27,00 & 0,23 & n.d. & $<0,05$ & 0,1 \\
\hline $\mathrm{Al}^{3+}\left(\mathrm{mg} \mathrm{L}^{-1}\right)$ & 0,17 & n.d. & n.d. & n.d. & n.d. & n.d. & 0,44 & 0,70 & n.d. & 0,06 & n.d. & n.d. & n.d. & $<0,05$ & 0,2 \\
\hline $\mathrm{Ba}^{2+}\left(\mathrm{mg} \mathrm{L}^{-1}\right)$ & 0,14 & n.d. & 0,55 & 0,17 & 0,09 & 0,40 & n.d. & 1,10 & 0,09 & 0,16 & 3,20 & 1,10 & n.d. & $<0,05$ & 1 \\
\hline $\mathrm{Cd}^{2+}\left(\mathrm{mg} \mathrm{L}^{-1}\right)$ & n.d. & n.d. & n.d. & n.d. & n.d. & n.d. & n.d. & 0,08 & n.d. & n.d. & n.d. & n.d. & n.d. & $<0,05$ & 0,005 \\
\hline $\mathrm{Cr}^{6+}\left(\mathrm{mg} \mathrm{L}^{-1}\right)$ & n.d. & n.d. & n.d. & n.d. & n.d. & n.d. & n.d. & n.d. & n.d. & n.d. & n.d. & n.d. & n.d. & $<0,05$ & n.e. \\
\hline $\mathrm{Cu}^{2+}\left(\mathrm{mg} \mathrm{L}^{-1}\right)$ & n.d. & n.d. & n.d. & n.d. & n.d. & n.d. & n.d. & n.d. & n.d. & n.d. & n.d. & n.d. & n.d. & $<0,05$ & 1 \\
\hline $\mathrm{Hg}^{2+}\left(\mathrm{mg} \mathrm{L}^{-1}\right)$ & n.d. & n.d. & n.d. & n.d. & n.d. & n.d. & 0,17 & 0,44 & n.d. & n.d. & 0,27 & n.d. & 0,20 & $<0,10$ & 1 \\
\hline $\mathrm{Mo}^{4+}\left(\mathrm{mg} \mathrm{L}^{-1}\right)$ & n.d. & n.d. & 0,11 & n.d. & n.d. & n.d. & n.d. & 0,21 & n.d. & n.d. & n.d. & n.d. & n.d. & $<0,05$ & n.e. \\
\hline $\mathrm{Pb}^{2+}\left(\mathrm{mg} \mathrm{L}^{-1}\right)$ & n.a. & n.a. & n.a. & n.a. & n.a. & n.a. & n.a. & n.a. & n.a. & n.a. & n.a. & n.a. & n.a. & $<0,05$ & 0,05 \\
\hline $\mathrm{Sn}^{2+}\left(\mathrm{mg} \mathrm{L}^{-1}\right)$ & n.d. & n.d. & n.d. & n.d. & n.d. & n.d. & n.d. & 0,10 & n.d. & n.d. & n.d. & n.d. & n.d. & $<0,05$ & n.e. \\
\hline $\mathrm{Sr}^{2+}\left(\mathrm{mg} \mathrm{L}^{-1}\right)$ & n.d. & n.d. & n.d. & n.d. & n.d. & n.d. & n.d. & 0,43 & n.d. & n.d. & n.d. & n.d. & n.d. & $<0,05$ & n.e. \\
\hline $\mathrm{Ti}^{2+}\left(\mathrm{mg} \mathrm{L}^{-1}\right)$ & n.d. & n.d. & n.d. & n.d. & n.d. & n.d. & n.d. & n.d. & n.d. & n.d. & n.d. & n.d. & n.d. & $<0,05$ & n.e. \\
\hline $\mathrm{V}^{3+}\left(\mathrm{mg} \mathrm{L}^{-1}\right)$ & n.d. & n.d. & n.d. & n.d. & n.d. & n.d. & n.d. & n.d. & n.d. & n.d. & n.d. & n.d. & n.d. & $<0,05$ & n.e. \\
\hline $\mathrm{Zn}^{2+}\left(\mathrm{mg} \mathrm{L}^{-1}\right)$ & n.d. & n.d. & 0,06 & n.d. & n.d. & n.d. & n.d. & 0,38 & n.d. & n.d. & n.d. & n.d. & n.d. & $<0,05$ & 5 \\
\hline $\mathrm{Zr}^{2+}\left(\mathrm{mg} \mathrm{L}^{-1}\right)$ & n.d. & n.d. & n.d. & n.d. & n.d. & n.d. & n.d. & n.d. & n.d. & n.d. & n.d. & n.d. & n.d. & $<0,05$ & n.e. \\
\hline
\end{tabular}

n.d. concentração não detectada pelo método analítico utilizado

n.e. valor não estabelecido

n.a. parâmetro não analisado

(*) concentração expressa como nitrato 
TABELA 2 - Resultados analíticos das águas subterrâneas das seis campanhas de monitoramento - continuação ( $3^{\mathrm{a}}$ a $6^{\mathrm{a}}$ campanhas).

\begin{tabular}{|c|c|c|c|c|c|c|c|c|c|c|c|c|c|c|c|}
\hline Parâmetro & $\begin{array}{c}\text { PM- } \\
01\end{array}$ & $\begin{array}{l}\text { PM- } \\
02\end{array}$ & $\begin{array}{c}\text { PM- } \\
03\end{array}$ & $\begin{array}{c}\text { PM- } \\
04\end{array}$ & $\begin{array}{l}\text { PM- } \\
05\end{array}$ & $\begin{array}{l}\text { PM- } \\
06\end{array}$ & $\begin{array}{c}\text { PM- } \\
07\end{array}$ & $\begin{array}{c}\text { PM- } \\
08\end{array}$ & $\begin{array}{l}\text { PM- } \\
09\end{array}$ & $\begin{array}{c}\text { PM- } \\
10\end{array}$ & $\begin{array}{c}\text { PM- } \\
11\end{array}$ & $\begin{array}{l}\text { PM- } \\
12\end{array}$ & $\begin{array}{c}\text { PC- } \\
01\end{array}$ & $\begin{array}{c}\text { Limite } \\
\text { de } \\
\text { detecção }\end{array}$ & $\begin{array}{c}\text { Padrões } \\
\text { de } \\
\text { qualidade }\end{array}$ \\
\hline \multicolumn{16}{|c|}{$3^{\text {a }}$ Campanha (08 de setembro de 2000$)$} \\
\hline Cond. Elétrica $\left(\mu \mathrm{S} \mathrm{cm}^{-1}\right)$ & 49,6 & 25,0 & $1.030,0$ & 52,2 & 38,9 & 200,5 & 34,9 & 407,0 & $1.008,0$ & 390,0 & $1.748,0$ & 969,0 & 18,2 & n.e. & n.e. \\
\hline $\mathrm{pH}$ & 5,56 & 5,30 & 5,66 & 5,61 & 5,00 & 4,56 & 5,71 & 4,81 & 4,46 & 5,22 & 5,50 & 4,63 & 5,37 & n.e. & n.e. \\
\hline Temp. $\left({ }^{\circ} \mathrm{C}\right)$ & 23,8 & 23,7 & 22,9 & 23,2 & 23,3 & 22,7 & 23,7 & 22,9 & 22,3 & 23,2 & 22,0 & 20,7 & 22,0 & n.e. & n.e. \\
\hline $\mathrm{Cl}^{-}\left(\mathrm{mg} \mathrm{L}^{-1}\right)$ & 30,00 & 27,00 & 220,00 & 23,00 & 23,00 & 43,00 & 11,00 & 53,00 & 128,00 & 73,00 & 442,00 & 254,00 & 11,00 & $<0,50$ & 250 \\
\hline $\mathrm{SO}_{4}{ }^{2-}\left(\mathrm{mg} \mathrm{L}^{-1}\right)$ & 2,10 & 7,00 & 69,00 & 1,20 & 0,70 & 2,00 & n.d. & 10,00 & 7,30 & 3,40 & 5,00 & 3,40 & 1,10 & $<0,50$ & 400 \\
\hline $\mathrm{NH}_{4}^{+}\left(\mathrm{mg} \mathrm{L}^{-1}\right)$ & 0,30 & 0,04 & 4,60 & 0,25 & 0,06 & 0,18 & 0,05 & 16,00 & 7,30 & 0,81 & 12,00 & 0,96 & n.d. & $<0,01$ & n.e. \\
\hline $\mathrm{NO}_{3^{-}}^{-}\left(\mathrm{mg} \mathrm{L}^{-1}\right)\left(^{*}\right)$ & n.d. & n.d. & 116,00 & 2,70 & n.d. & 13,00 & 0,60 & 40,00 & 122,00 & 14,00 & 127,00 & 59,00 & n.d. & $<0,50$ & 10 \\
\hline $\mathrm{NO}_{2}^{-}\left(\mathrm{mg} \mathrm{L}^{-1}\right)$ & n.d. & n.d. & n.d. & n.d. & n.d. & n.d. & n.d. & n.d. & n.d. & n.d. & n.d. & n.d. & n.d. & $<0,50$ & n.e. \\
\hline \multicolumn{16}{|c|}{$4^{\mathrm{a}}$ Campanha (28 de outubro de 2000$)$} \\
\hline Cond. Elétrica $\left(\mu \mathrm{S} \mathrm{cm}^{-1}\right)$ & 70,2 & 11,8 & 964,0 & 35,5 & 25,0 & 133,0 & 20,4 & 162,0 & 270,0 & 348,0 & $1.910,0$ & 934,0 & 17,2 & n.e. & n.e. \\
\hline $\mathrm{pH}$ & 5,80 & 5,22 & 5,71 & 5,26 & 4,97 & 4,58 & 5,01 & 4,29 & 4,51 & 4,96 & 4,59 & 4,52 & 5,20 & n.e. & n.e. \\
\hline Temp. $\left({ }^{\circ} \mathrm{C}\right)$ & 24,1 & 23,2 & 22,7 & 23,6 & 23,3 & 23,6 & 23,3 & 23,4 & 23,0 & 22,4 & 21,6 & 21,7 & 23,6 & n.e. & n.e. \\
\hline $\mathrm{Cl}^{-}\left(\mathrm{mg} \mathrm{L}^{-1}\right)$ & n.d. & n.d. & 190,00 & 4,80 & 1,00 & 34,00 & 0,75 & 27,00 & 53,00 & 97,00 & 584,00 & 258,00 & 1,30 & $<0,50$ & 250 \\
\hline $\mathrm{SO}_{4}{ }^{2-}\left(\mathrm{mg} \mathrm{L}^{-1}\right)$ & 0,71 & 8,90 & 43,00 & 0,87 & 1,30 & 2,50 & 0,67 & 15,00 & 4,30 & 3,40 & 4,60 & 6,30 & n.d. & $<0,50$ & 400 \\
\hline $\mathrm{NH}_{4}^{+}\left(\mathrm{mg} \mathrm{L}^{-1}\right)$ & n.d. & 2,00 & 2,80 & n.d. & n.d. & n.d. & 0,14 & 0,54 & 0,10 & 0,80 & 26,50 & 0,58 & 0,20 & $<0,01$ & n.e. \\
\hline $\begin{array}{c}\mathrm{NO}_{3}^{-} \\
\left(\mathrm{mg} \mathrm{L}^{-1}\right)\left(^{*}\right)\end{array}$ & n.d. & n.d. & n.d. & 2,00 & n.d. & 3,20 & n.d. & 9,10 & 50,00 & 2,90 & 38,00 & 38,00 & 0,50 & $<0,50$ & 10 \\
\hline $\mathrm{NO}_{2}^{-}\left(\mathrm{mg} \mathrm{L}^{-1}\right)$ & n.d. & n.d. & n.d. & n.d. & n.d. & n.d. & n.d. & n.d. & n.d. & n.d. & n.d. & n.d. & n.d. & $<0,50$ & n.e. \\
\hline \multicolumn{16}{|c|}{$5^{\text {a }}$ Campanha (03 de dezembro de 2000) } \\
\hline Cond. Elétrica $\left(\mu \mathrm{S} \mathrm{cm}^{-1}\right)$ & 53,1 & 13,9 & 890,0 & 39,3 & 37,0 & 175,8 & 50,4 & 132,2 & 508,0 & 330,0 & $1.929,0$ & $1.063,0$ & 19,2 & n.e. & n.e. \\
\hline $\mathrm{pH}$ & 5,60 & 5,35 & 6,02 & 5,36 & 5,52 & 4,40 & 5,04 & 4,79 & 4,36 & 5,09 & 4,97 & 4,64 & 5,33 & n.e. & n.e. \\
\hline Temp. $\left({ }^{\circ} \mathrm{C}\right)$ & 23,8 & 23,7 & 22,9 & 23,2 & 23,4 & 22,7 & 22,9 & 22,3 & 23,3 & 23,3 & 22,0 & 20,7 & 22,0 & n.e. & n.e. \\
\hline Alc $\left(\mathrm{mg} \mathrm{L}^{-1}\right)$ & 55 & 12 & 139 & 23 & 21 & 9,1 & 6 & 17 & n.d. & 45 & 13 & 13 & 20 & n.e. & n.e. \\
\hline $\mathrm{Na}^{+}\left(\mathrm{mg} \mathrm{L}^{-1}\right)$ & 5,70 & 0,62 & 78,00 & 2,40 & 41,30 & 41,00 & 1,80 & 6,40 & 71,00 & 26,00 & 320,00 & 97,00 & 0,31 & $<0,05$ & n.e. \\
\hline $\mathrm{Cl}^{-}\left(\mathrm{mg} \mathrm{L}^{-1}\right)$ & 5,00 & n.d. & 125,00 & n.d. & n.d. & 44,00 & n.d. & 20,00 & 77,00 & 87,00 & 648,00 & 236,00 & n.d. & $<0,50$ & 250 \\
\hline $\mathrm{K}^{+}\left(\mathrm{mg} \mathrm{L}^{-1}\right)$ & 1,58 & 0,35 & 41,10 & 5,30 & 1,10 & 1,50 & 1,80 & 1,40 & 1,20 & 5,50 & 31,00 & 23,00 & 1,00 & $<0,05$ & n.e. \\
\hline $\mathrm{Ca}^{2+}\left(\mathrm{mg} \mathrm{L}^{-1}\right)$ & 1,39 & 0,13 & 21,40 & 3,30 & 1,20 & 2,40 & 0,98 & 47,9 & 11,00 & 11,00 & 49,00 & 34,00 & 0,63 & $<0,05$ & n.e. \\
\hline $\mathrm{Mg}^{2+}\left(\mathrm{mg} \mathrm{L}^{-1}\right)$ & 0,91 & 0,24 & 22,70 & 5,30 & 0,97 & 4,20 & 1,30 & 3,20 & 6,00 & 0,25 & 44,00 & 28,00 & 0,58 & $<0,05$ & \\
\hline $\mathrm{SO}_{4}{ }^{2-}\left(\mathrm{mg} \mathrm{L}^{-1}\right)$ & 7,40 & 2,00 & 12,00 & 1,20 & 4,30 & 4,00 & 11,00 & 5,00 & 3,80 & 5,40 & 4,70 & 7,90 & 1,10 & $<0,50$ & 400 \\
\hline $\begin{array}{c}\mathrm{NH}_{4}^{+} \\
\left(\mathrm{mg} \mathrm{L}^{-1}\right)\end{array}$ & n.d. & n.d. & 0,24 & 0,62 & 0,53 & 1,00 & 0,14 & 0,74 & n.d. & 0,92 & 1,30 & 0,20 & 1,50 & $<0,01$ & n.e. \\
\hline $\mathrm{NO}_{3}^{-}\left(\mathrm{mg} \mathrm{L}^{-1}\right)\left(^{*}\right)$ & 1,00 & n.d. & n.d. & 2,00 & n.d. & 12,00 & 0,96 & 23,00 & 103,00 & 8,70 & 45,00 & 57,00 & 4,50 & $<0,50$ & 10 \\
\hline $\mathrm{NO}_{2}^{-}\left(\mathrm{mg} \mathrm{L}^{-1}\right)$ & n.d. & n.d. & n.d. & n.d. & n.d. & n.d. & n.d. & n.d. & n.d. & n.d. & n.d. & n.d. & n.d. & $<0,50$ & n.e. \\
\hline N Kjeldahl (mg L-1) & n.d. & n.d. & n.d. & n.d. & n.d. & n.d. & n.d. & 17,00 & 19,00 & 2,10 & 1,70 & n.d. & n.d. & $<0,10$ & n.e. \\
\hline $\begin{array}{c}\mathrm{N} \text { amoniacal } \\
\left(\mathrm{mg} \mathrm{L}^{-1}\right)\end{array}$ & n.d. & n.d. & 0,24 & 0,62 & 0,53 & 1,00 & 0,14 & 0,74 & n.d. & 0,92 & 1,30 & 0,20 & 1,50 & $<0,02$ & n.e. \\
\hline \multicolumn{16}{|c|}{$6^{\text {a }}$ Campanha (06 de janeiro de 2001) } \\
\hline Cond. Elétrica $\left(\mu \mathrm{S} \mathrm{cm}^{-1}\right)$ & 64,4 & 14,8 & $1.045,0$ & 89,6 & 67,8 & 187,8 & 29,8 & 233,0 & 552,7 & 342,0 & $1.827,0$ & 972,0 & 17,0 & n.e. & n.e. \\
\hline $\mathrm{pH}$ & 5,48 & 5,30 & 5,75 & 5,46 & 4,70 & 4,28 & 5,18 & 4,57 & 4,47 & 4,60 & 4,84 & 4,87 & 4,50 & n.e. & n.e. \\
\hline Temp. $\left({ }^{\circ} \mathrm{C}\right)$ & 23,8 & 23,7 & 22,9 & 23,2 & 23,3 & 22,7 & 23,7 & 22,9 & 22,3 & 23,2 & 22,0 & 20,7 & 22,0 & n.e. & n.e. \\
\hline $\mathrm{Cl}^{-}\left(\mathrm{mg} \mathrm{L}^{-1}\right)$ & 0,72 & 0,76 & 236,00 & 25,00 & 1,20 & 32,00 & 1,50 & 45,00 & 24,00 & 27,00 & 384,00 & 174,00 & n.d. & $<0,50$ & 250 \\
\hline $\mathrm{SO}_{4}^{2-}\left(\mathrm{mg} \mathrm{L}^{-1}\right)$ & 2,10 & 1,40 & 69,00 & 20,00 & 1,40 & 3,20 & 0,98 & 5,90 & 2,00 & 2,10 & 19,00 & 43,00 & n.d. & $<0,50$ & 400 \\
\hline $\mathrm{NH}_{4}^{+}\left(\mathrm{mg} \mathrm{L}^{-1}\right)$ & 0,81 & 1,20 & 1,10 & 0,16 & 0,60 & 0,11 & 0,22 & 0,30 & 1,70 & 0,72 & 4,50 & 0,24 & n.d. & $<0,01$ & n.e. \\
\hline $\mathrm{NO}_{3}^{-}\left(\mathrm{mg} \mathrm{L}^{-1}\right)\left(^{*}\right)$ & n.d. & n.d. & 15,00 & n.d. & n.d. & 4,80 & n.d. & 45,00 & 20,00 & 11,00 & 8,40 & 10,00 & 0,4 & $<0,50$ & 10 \\
\hline $\mathrm{NO}_{2}^{-}\left(\mathrm{mg} \mathrm{L}^{-1}\right)$ & n.d. & n.d. & n.d. & n.d. & n.d. & n.d. & n.d. & n.d. & n.d. & n.d. & n.d. & n.d. & n.d. & $<0,50$ & n.e. \\
\hline
\end{tabular}

n.d. concentração não detectada pelo método analítico utilizado n.e. valor não estabelecido

(*) concentração expressa como nitrato 


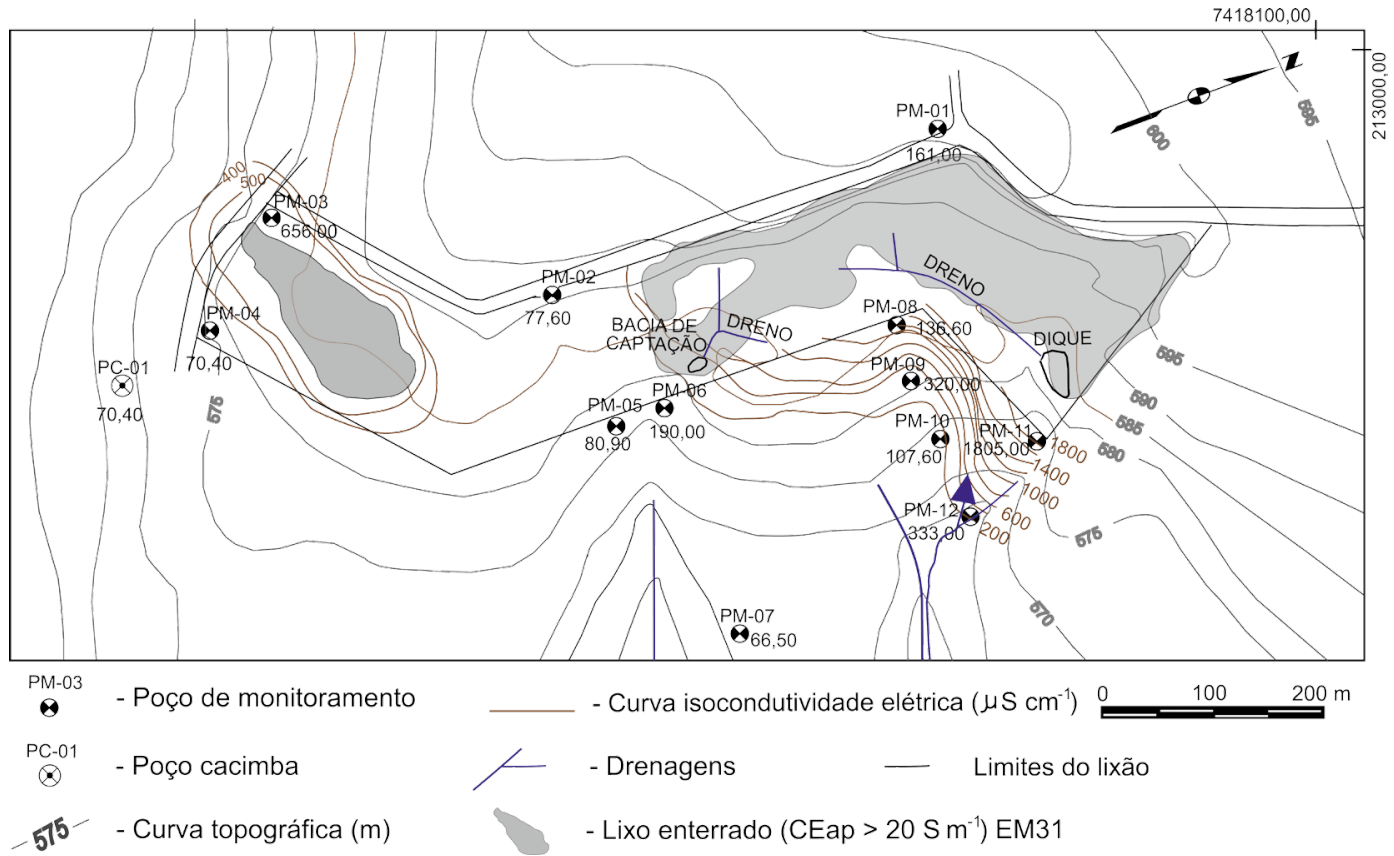

FIGURA 12 - Isovalores de condutividade elétrica (CE) em agosto de 2000.

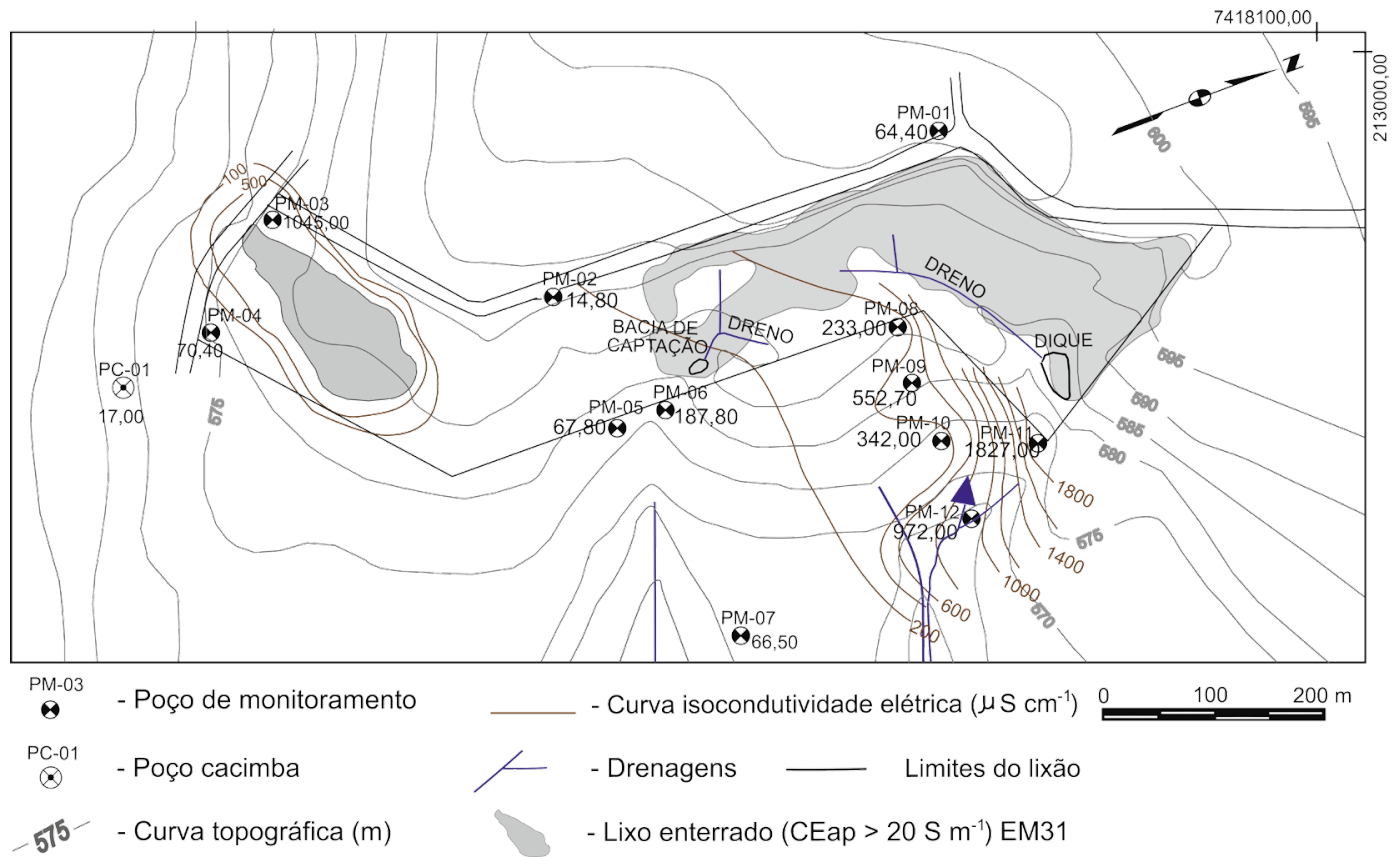

FIGURA 13 - Isovalores de condutividade elétrica (CE) em janeiro de 2001.

Na porção central do lixão, o impacto nas águas subterrâneas é menor, devido à distribuição e menor quantidade de lixo nesta área. Entretanto, após o início das chuvas a pluma avança devido à maior lixiviação (Figura 13). Mas a 200 m a jusante, no PM-07, as CE estão sempre abaixo de $100 \mu \mathrm{S} \mathrm{cm}^{-1}$. Em contraste, a área norte do lixão é a mais impactada devido a grande quantidade de resíduo ali depositado. $\mathrm{O}$ lixo ocupa toda esta área que está muito próxima das surgências que formam o córrego a jusante do lixão. 
Na porção sul, o lixo foi lançado sobre a área do divisor das águas subterrâneas, entretanto não há indicação de contaminação importante no PM-04 (pequeno aumento na concentração de cloreto na época de chuvas) (Figuras 12 e 13). Provavelmente, a pluma resultante destes resíduos dirigem-se para NNE, como indica os resultados das anomalias eletromagnéticas com uso do EM34 (Figura 8).

\subsubsection{Distribuição da contaminação}

Os resultados das análises químicas evidenciam que o chorume do lixão impacta o aquífero. Os parâmetros $\mathrm{Cl}^{-}, \mathrm{Fe}^{3+}, \mathrm{NO}_{3}^{-}, \mathrm{Mn}^{2+}, \mathrm{Al}^{3+}$ e $\mathrm{Ba}^{2+}$ (Tabela 2) apresentaram concentrações acima das permitidas pela legislação (Portaria do Ministério da Saúde 2914 de 2011) em alguns poços, caracterizando estas águas como impróprias para o consumo humano.

As águas menos mineralizadas $(\mathrm{CE}<100$ $\mu \mathrm{S} \mathrm{cm}^{-1}$ ) foram classificadas como bicarbonatadas mistas, comuns ao Sistema Aquífero Tubarão (DAEE 1981), e as águas contaminadas (CE > 100 $\mu \mathrm{S} \mathrm{cm}^{-1}$ ), como cloretadas-(nitratadas)-sódicas, com uma clara associação aos chorumes de lixões domésticos (SANTOS FILHO 2001, OLLA et al. 2015). Os parâmetros $\mathrm{Cl}^{-}, \mathrm{Na}^{+}, \mathrm{Ca}^{2+}, \mathrm{Mg}^{2+}, \mathrm{K}^{+}$, $\mathrm{NH}_{4}^{+}, \mathrm{NO}_{3}^{-}, \mathrm{Fe}^{3+}, \mathrm{Mn}^{2+}$ e alcalinidade possuem concentrações superiores a $5,0 \mathrm{mg} \mathrm{L}^{-1}$, sendo o cloreto e o sódio os mais marcantes e, secundariamente, o cálcio e magnésio.

$\mathrm{O}$ restante dos metais presentes ocorre em concentrações muito baixas e praticamente não são significativas para a área. Entretanto, nota-se que alguns metais pesados $\left(\mathrm{Cd}^{2+}, \mathrm{Mo}^{4+}, \mathrm{Sn}^{2+}, \mathrm{Sr}^{2+} \mathrm{e}\right.$ $\mathrm{Zn}^{2+}$ ) encontram-se quase que exclusivamente nas porções norte e sul, áreas estas onde maiores quantidades de resíduos sólidos foram depositados. Os parâmetros nitrogenados $\left(\mathrm{NH}_{4}^{+}, \mathrm{NO}_{3}^{-}\right.$e $\left.\mathrm{NO}_{2}^{-}\right)$também apresentam o mesmo comportamento (PM08, PM-09, PM-11 e PM-12). Vale mencionar que na porção norte também havia valas de deposição de resíduos hospitalares, resíduos de indústria (ricos em matéria orgânica) e o dique de captação de chorume que escoa pelo lixão (Tabela 2).

A relação entre as concentrações de $\mathrm{NH}_{4}^{+}$/ $\mathrm{NO}_{3}^{-}$pode denotar ambientes menos oxidantes, que são comuns aos lixões. Ambientes mais reduzidos foram observados nos limites da área de deposição do lixão (PM-08 e PM-11), ou mesmo a jusante (PM-09 e PM-12), creditando-se o fato provavelmente ao excesso de carbono, originado pelo próprio lixo e à baixa permeabilidade do ma- terial geológico, que restringe o acesso do oxigênio atmosférico. Dentro da faixa de $\mathrm{pH}$ observado na área $(4,28$ a 6,40), os metais são pouco móveis. Sendo assim, suas presenças estão restritas às proximidades do lixão, até onde as condições redutoras favoreceram sua mobilidade. Assim, têm-se que os metais $\left(\mathrm{Fe}^{2+}, \mathrm{Al}^{3+}, \mathrm{Mn}^{2+}\right.$ e $\left.\mathrm{Ba}^{2+}\right)$ e metais pesados ocorrem principalmente nos PM-03, PM-08 e PM-11.

A tendência geral para os poços impactados é o aumento das concentrações de todos os constituintes com o incremento das precipitações a partir do início das chuvas (a partir de outubro), mostrando o maior aporte de sais, com a lixiviação do lixo, como já demostrava os valores de CE (Figura 11).

O cloreto, sendo um íon conservativo e móvel, se presta ao acompanhamento da hidráulica do sistema, e também da distribuição da pluma de contaminação na área de estudo. $\mathrm{O}$ cloreto $\mathrm{e}$ o sódio apresentam boa correlação com as distribuições das condutividades elétricas. Há também uma boa correlação entre os resultados das anomalias eletromagnéticas obtidas nos CEM rasos (Figura 6), confirmando que esses métodos geofísicos se prestam à delineação da pluma contaminante. O uso de diferentes técnicas e arranjos aplicam-se à identificação tridimensional das áreas com mais lixo e à distribuição espacial da pluma contaminante na zona saturada do aquífero.

\section{CONCLUSÕES}

Os métodos diretos de investigação aplicados nesse estudo foram mais conclusivos que as técnicas indiretas para a determinação da contaminação da água subterrânea, entretanto a aplicação das técnicas geofísicas, foi mais rápida, de menor custo e com bons resultados na identificação de resíduos enterrados e da contaminação na zona não saturada. O EM34 não detectou anomalias na zona saturada do aquífero, quando essas encontravam-se a mais de $8 \mathrm{~m}$ de profundidade, pois as altas resistividades do aquitarde, resultaram em $\mathrm{CE}_{\text {ap }}$ globais inferiores às do background. $\mathrm{O}$ conjunto destes resultados também provaram que a contaminação do solo e das águas subterrâneas, embora existam, estão restritas à área do próprio Vazadouro ou muito próximas dele.

As amostras de água subterrânea extraídas de poços de monitoramento confirmaram que há impactos do lixiviado nas águas subterrâneas para 
os parâmetros $\mathrm{Cl}^{-}, \mathrm{Fe}^{3+}, \mathrm{NO}_{3}^{-}, \mathrm{Mn}^{2+}, \mathrm{Al}^{3+}$ e $\mathrm{Ba}^{2+}$. Outros metais pesados, embora presentes, não foram detectados em concentrações maiores que os padrões de potabilidade para a água.

Dos resultados deste estudo, foi possível concluir que os métodos indiretos devem ser usados em dois momentos: i) para auxiliar na locação dos poços de monitoramento de água subterrânea e ii) para assistir na interpretação e integração dos dados obtidos pela própria rede de monitoramento, com a construção do modelo conceitual de fluxo e contaminação do aquífero; desta forma, podem ser aplicados novamente em campo para cobrir áreas ou aspectos não avaliados em uma primeira campanha. Portanto, tais métodos têm funções bastante complementares em um estudo de contaminação de resíduos sólidos municipais, como o apresentado.

\section{AGRADECIMENTOS}

Os autores querem expressar seu agradecimento ao Geól. Marcus Ucci pelas primeiras revisões críticas a este artigo. Da mesma forma, os autores expressam sua gratidão ao serviço dos relatores da Revista.

\section{REFERÊNCIAS BIBLIOGRÁFICAS}

APHA - AMERICAN PUBLIC HEALTH ASSOCIATION. 1999. Standard methods for the examination of water and wastewater. APHA/AWWA/WEF, Washington, 20 $0^{\text {th }}$ edition.

BASOKUR, A.T. 1990. Microcomputer program for the direct interpretation of resistivity sounding data. Computer and Geosciences, 16(4): 587-601.

CEPAGRI - CENTRO DE PESQUISAS METEOROLÓGICAS E CLIMÁTICAS APLICADAS À AGRICULTURA. 2016. Clima dos Municípios Paulistas. Universidade Estadual de Campinas - UNICAMP, São Paulo. Disponível em http://www.cpa.unicamp.br/outras-informacoes/clima_muni_606.html. Acessado em 23 out. 2016.

DAEE - DEPARTAMENTO DE ÁGUAS E ENERGIA ELÉTRICA. 1981. Estudo de águas subterrâneas - Região Administrativa 5 - Campinas. Departamento de Águas e
Energia Elétrica, Diretoria de Planejamento e Controle, São Paulo, v. 2, 112 p.

DAEE/IG/IPT/CPRM - DEPARTAMENTO DE ÁGUAS E ENERGIA ELÉTRICA / INSTITUTO GEOLÓGICO DE SÃO PAULO / INSTITUTO DE PESQUISAS TECNOLÓGICAS DE SÃO PAULO / SERVIÇO GEOLÓGICO DO BRASIL. 2005. Mapa de Águas Subterrâneas do Estado de São Paulo, escala 1:1.000.000. DAEE/IG/IPT/ CPRM, São Paulo, 3 v.

FREEZE,A.R.; CHERRY, J.A. 1979. Groundwater. Prentice Hall, New Jersey, 604 p.

GIMENEZ, N.L.B. 1996. Estudo petrológico dos arenitos da Formação Tatuí no Estado de São Paulo. Instituto de Geociências e Ciências Exatas, UNESP, Rio Claro, Dissertação de Mestrado, $174 \mathrm{p}$.

GOLDEN SOFTWARE. 2016. Software Surfer. http://www.goldensoftware.com/products/ surfer.

GREENHOUSE, J.P.; SLAINE, D.D. 1983. The use of Reconnaissance Electromagnetic Methods to Map Contaminant Migration. Ground Water Monitoring Review, 3(2): 47-59.

GREENHOUSE, J.P.; SLAINE, D.D.; GUDJURGIS, P. 1998. Application of Geophysics in Environmental Investigations. Matrix Multimedia, Canada. CD-ROM.

GUIGUER, N. 1987. Poluição das águas subterrâneas causadas por aterros sanitários: uma abordagem matemático-experimental. Escola Politécnica, Universidade de São Paulo, São Paulo, Dissertação de Mestrado, 250 p.

HIRATA, R.; FOSTER, S.; OLIVEIRA, F. 2015. Águas subterrâneas urbanas no Brasil: avaliação para uma gestão sustentável. Instituto de Geociências/USP e FAPESP, São Paulo, v. 1, $1^{\text {a }}$ ed., $112 \mathrm{p}$.

HUTCHINSON, P.; BARTA, L. 2000. Geophysical applications to solid waste analysis. In: I. Zandi, R.L Mersky, W.K. Shieh (eds.) Proceedings of the Sixteenth International Conference on Solid Waste Technology and Management Philadelphia, PA, U.S.A., December $10-13$, p. $2-68$ to 2-78. 
IG/CETESB/DAEE - INSTITUTO GEOLÓGICO / COMPANHIA DE TECNOLOGIA DE SANEAMENTO AMBIENTAL / DEPARTAMENTO DE ÁGUAS E ENERGIA ELÉTRICA. 1997. Mapeamento da vulnerabilidade e risco de poluição das águas subterrâneas no Estado de São Paulo (Série de Documentos), escala 1:1.000.000. IG/CETESB, São Paulo, 2 v., 129 p.

IPT - INSTITUTO DE PESQUISAS TECNOLÓGICAS DE SÃO PAULO. 1981. Mapa geológico do Estado de São Paulo, escala 1: 500.000. IPT/DMGA, São Paulo.

MONIER-WILLIAMS, M.E.; GREENHOUSE, J.P.; MENDES, J.M.; ELLERT, N. 1990. Terrain conductivity mapping with topographic corrections at three waste disposal sites in Brazil. Geotechnical and Environmental Geophysics, Society of Exploration Geophysicists, 2: 41-55.

OKOLIE, E.; ATAKPO, E.; OKPIKORO, F. 2010. Application of linear Schlumberger configuration in delineation of formation strata and groundwater distribution in Ifon Ondo State, Nigeria. International Journal of the Physical Sciences, 5(6): 642-650.

OLLA, T.; AYOKUNLE, A.; AKINLALU, A.; GBENGA, M.; ADEBOWALE, O.; ADELUSI, K.;ADIAT,A.2015. Geophysical and Hydrochemical Investigation of a Municipal Dumpsite in Ibadan, Southwest
Nigeria. Journal of Environment and Earth Science, 5(14): 200-215.

ROSS, J.L.S.; MOROZ, I.C. 1997. Mapa geomorfológico do Estado de São Paulo, escala 1:500.000. FFLCH-USP/IPT/FAPESP, São Paulo.

SANTOS FILHO, M.G. 2001. O impacto na qualidade das águas subterrâneas gerado pela disposição inadequada de resíduos sólidos urbanos no município de Tatuí - SP. Instituto de Geociências, Universidade de São Paulo, São Paulo, Dissertação de Mestrado, 115 p.

SIDHARDHAN, S.; ADISHKUMAR, S.; JAYGANESH, D. 2015. A Geophysical Investigation of Resistivity and Groundwater Quality near a Corporate Solid Waste Dump. Polish Journal Environmental Studies, 24(6): 2761-2766.

SOUPIOS, P.; PAPADOPOULOS, N.; PAPADOPOULOS, I.; MANIOS, T. 2007. Application of Integrated Methods in Mapping Waste Disposal Areas. Environmental Geology, 53(3): 522-531.

TELFORD W.M.; GELDART L.P.; SHERIFF, R.E 1990. Applied Geophysics. Cambridge University Press, London, 622 p.

THORNTHWAITE, C.; MATHER, J. 1955. The water balance. Centerton, NJ, Laboratory of Climatology. Publications in Climatology, 8(1): 1-104.

Endereço dos autores:

Manoel Gomes dos Santos Filho - Centro Universitário Fundação Santo André, Faculdade de Engenharia (FAENG/CUFSA), Avenida Príncipe de Gales, 821 Príncipe de Gales, CEP: 09060-650, Santo André, SP, Brasil.E-mail:manoel.gomes@fsa.com.br

Ricardo Hirata - Universidade de São Paulo, Centro de Pesquisas em Águas Subterrâneas - CEPAS/USP, Rua do Lago, 562, Cidade Universitária, CEP: 05508-080, São Paulo, SP. E-mail: rhirata@usp.br

Mariana Bernardino Luiz e Bruno Pirilo Conicelli - Universidade de São Paulo, Instituto de Geociências, Laboratório de Modelos Físicos - LAMO/CEPAS, Rua do Lago, 562, Cidade Universitária, CEP: 05508-080, São Paulo, SP. E-mails: mariana.bluiz@hotmail.com; bconicelli@gmail.com

Artigo submetido em 02 de março de 2017, aceito em 29 de maio de 2017. 